\title{
Escritura, Serpientes de Guerra y culto al Dios del Maíz en un sector de la región Puuc
}

\author{
Writing, War Serpents and Worship \\ of the Maize God in a Sector \\ of the Puuc Region
}

\author{
David Azael García Nava
}

Investigador independiente, México

\begin{abstract}
Resumen: La presente contribución muestra los resultados obtenidos a partir del estudio de inscripciones e imágenes de algunos monumentos esculpidos en estilo Puuc Temprano procedentes de varios asentamientos arqueológicos del sector occidental, en sitios como Xcalumkín, Xcochá, Xculoc e Itzimté Bolonchén, este último perteneciente al sector oriental. La investigación permitió determinar, de manera preliminar, que varios señores subsidiaros o sajales, influenciados por los mayas del Usumacinta, representaban a la Serpiente de Guerra y otros más al Dios del MaízCacao. Ello en conjunto con diversos registros toponímicos llamativamente raros en estas latitudes, grupos jeroglíficos como K'ihn Ha', "Agua Caliente", y K'ihn Ajaw, "Señor Solar", detectados en Xcalumkín y vinculados con la región de Piedras Negras, o el reconocimiento del espacio sobrenatural Nah Ho' Chan Bob, "El Lugar Florido es el Primer Cinco Cielo", en una inscripción de Itzimté Bolonchén. También se identificó el Edificio de las Columnas Labradas de Xculoc con una geografía sagrada conocida como Wuk Chit K'an Nal, "Lugar del Siete... Precioso", asociada al culto del Dios del Maíz-Cacao y al árbol florido. El mensaje que deseamos transmitir en este ensayo es que a través del arte y la escritura varios dignatarios legitimaron su posición social al difundir imágenes, símbolos y discursos escriturarios poco conocidos para la región; así, el estudio ofrece nuevos episodios políticos y religiosos en la vida e historia cultural de los mayas del Puuc durante la primera mitad del siglo vilI.

Palabras clave: Sajal; Serpiente de Guerra; topónimos; Puuc Temprano; Dios del MaízCacao.
\end{abstract}

ABSTRACT: This contribution shows the results obtained from the study of the texts and images of some monuments carved in the Early Puuc style from several archaeo- 
logical settlements in the wester sector, in sites such as Xcalumkín, Xcochá, Xculoc and Itzimté Bolonchén, the latter belonging to the eastern sector of the area. The investigation allowed to identify that several subordinate or sajal lords, influenced by the maya of the Usumacinta represented the War Serpent and some others the God of the Maize-Cacao, in addition to several toponymic records strikingly rare in these latitudes of the Mayan area as well as hieroglyphic groups such as K'ihn Ha', "Hot Water", and K'ihn Ajaw, "Solar Lord", detected in Xcalumkín, linked to the Piedras Negras region. Also, the recognition of the supernatural place Nah Ho' Chan Bob, "The Flowery place is the First Five Heavens", in an inscription of Itzimte Bolonchen, in addition to identifying the Building of the Carved Columns of Xculoc, with a sacred space known as Wuk Chit K'an Nal, "Place of the Seven... Precious", associated with the cult of the God of Maize-Cacao and the flowery tree. The message we wish to present in this essay is that through art and writing, several dignitaries legitimized their social position by disseminating images, symbols and scriptural discourses not well known to this region. The study offers new political and religious episodes in the life and cultural history of the Puuc Maya during the first half of the 8th century.

KeYwords: Sajal; War Serpent; Toponyms; Early Puuc; Maize-Cacao God.

RECEPCIÓN: 5 de noviembre de 2019.

ACEPTACIÓN: 12 de diciembre de 2019.

Dor: https://doi.org/10.19130/iifl.ecm.2020.56.2.0002

\section{Introducción}

Diversos ejemplos jeroglíficos e iconográficos procedentes de varios soportes de mampostería en los sitios mayas de Xcalumkín, Xcochá, Xculoc e Itzimté Bolonchén ofrecen información significativa que nos encaminan a determinar cómo la clase dirigente y de alta jerarquía implementaba diversos métodos para promover su naturaleza divina, política y social al paso de las primeras décadas del siglo viII (Figura 1). Cabe señalar que los datos que a continuación se presentan ofrecen información novedosa, aunque por momentos se recogen estudios anteriores, pese a la difícil tarea que representa la labor de desciframiento de las inscripciones para esta región, pues en múltiples ocasiones los registros jeroglíficos no se han conservado satisfactoriamente; otras veces los escritos son extremadamente raros, o bien, resultan totalmente desconocidos.

De acuerdo con Pollock (1980), Gendrop (1983), Andrews (1986) y Vidal y Muñoz (1997), el estilo Puuc Temprano discurre en una temporalidad mayor a 650 d.C. y menor a 750 d.C., dependiendo del sitio desde el cual se observe. Se caracteriza por la implementación de nuevas técnicas constructivas y la elaboración y complejidad de los motivos decorativos, sobresaliendo el buen dominio de la mampostería; aparecen columnas cilíndricas bien definidas y capiteles cuadrados perfectamente recortados, distinguiéndose por el buen manejo y corte de los blo- 


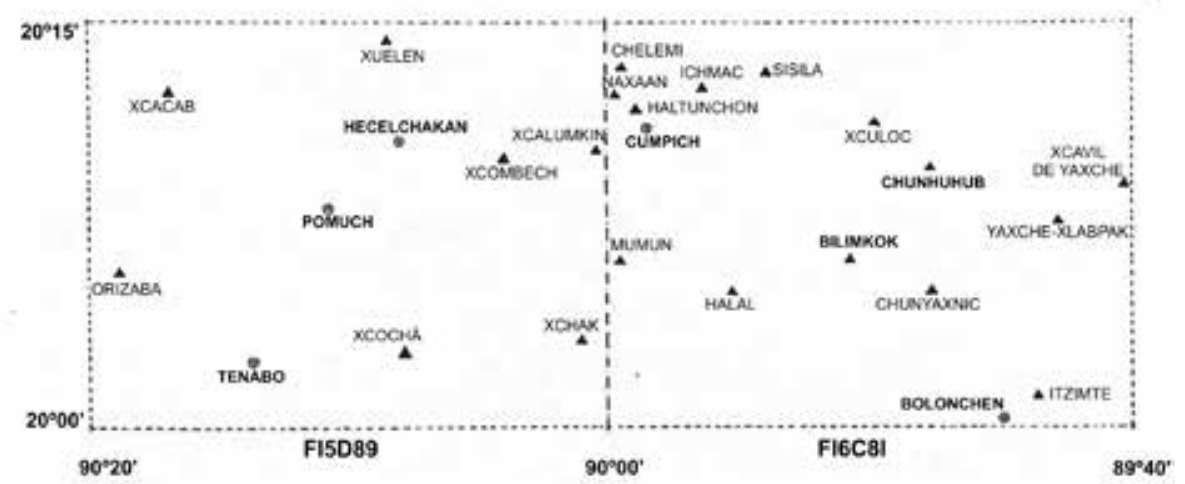

Figura 1. Algunos sitios Puuc de Campeche (según Benavides Castillo, 2000: 205, modificado por el autor).

ques para la construcción, y se incorporan cresterías con motivos geométricos al frente y centro de los edificios. En forma interesante, aparece en este horizonte estilístico, o más bien, es introducido, un complejo sistema escriturario, decorando así diversos soportes de carga, por ejemplo: columnas, jambas, dinteles, cornisas y capiteles esculpidos en bajo relieve, además de la culminación de los vistosos e imponentes portales jeroglíficos (Benavides, Novelo y Pallán, 2011).

En Xcalumkín e Itzimté-Bolonchén afortunadamente contamos con anotaciones calendáricas necesarias para datar con precisión el fenómeno en el tiempo, y en ambas demarcaciones las inscripciones más tempranas son prácticamente las mismas, 728 y 731 d.C. Para nuestro asombro la producción de inscripciones viene en detrimento durante la segunda mitad del siglo vilı. Hasta ahora, no se sabe con certeza qué razones o causas propiciaron este declive y mucho menos qué fue de la gente que ocupó las edificaciones de estilo Puuc Temprano, y por qué sus nombres, epítetos o cargos-rangos no vuelven a aparecer jamás en las inscripciones serranas; por el contrario, se vuelven invisibles. Y, si a este intrigante periodo constructivo agregamos la ausencia de entierros y ofrendas, estamos ante un panorama totalmente desconocido.

En trabajos anteriores, el autor de estas líneas (García Nava, 2017; s/f), revisó y planteó, con base en los resultados obtenidos por Becquelin, Michelet y Benavides (2011), que los gobernantes de la fase Xcalumkín Temprano fueron desplazados por un grupo de individuos identificados como sajales, mismos que se establecieron en Xcalumkín a principios del siglo viII, incorporando nuevas edificaciones de carácter concejil (edificios de poder), evento que tuvo lugar con la implementación del programa constructivo Puuc Temprano. En este sentido, es importante señalar que, antes del 728 d.C., no se conocen registros epigráficos que rindan cuenta del cargo-rango de sajal en los textos tempranos de la zona 
en discusión; este importante título subsidiario parece asociarse, de igual forma, con la introducción de la nueva corriente estilística. Por lo tanto, los resultados derivados en nuestra investigación muestran que miembros de la clase gobernante, identificados con el grado de sajal, reclaman su identidad por medio de elementos simbólicos y escriturarios claramente influenciados por los mayas del Usumacinta, con la excepción de varios gobernantes de Itzimté Bolonchén, que al parecer ostentaban el título k'uhul ajaw, "Divino Señor". Otras fuentes jeroglíficas brindan información útil que previamente se desconocían para estas vecindades y que vienen a dar luz sobre algunos aspectos religiosos que se conectan con diversas toponimias mitológicas relacionadas con el culto al Dios del Maíz-Cacao.

\section{Xcalumkín: insignias de guerra y topónimos foráneos (ca. 728-771)}

En trabajos previos (García Nava, 2017; s.f.), se ha propuesto que en Xcalumkín, en el transcurso del Clásico Tardío, la Serpiente de Guerra está presente en el arte en piedra, considerando que la implementación de la vestimenta y toda la parafernalia necesaria para evocarla, era exclusiva de los sajales ${ }^{1}$ quienes se identificaron con la icónica entidad sobrenatural. Además, se propuso que los dignatarios de la fase Puuc Temprano estaban fuertemente influenciados por la idiosincrasia ribereña del Alto Usumacinta, especialmente con la región de Piedras Negras (Yokib).

La llamada Serpiente de la Guerra tiene sus orígenes en el Clásico Temprano y sin lugar a duda fue introducida por los teotihuacanos al área maya en los inicios del siglo Iv, donde rápidamente la entidad sobrenatural evocaría una institución militar (Taube, 1992; Stuart, 2000; Martin, 2001; Martin y Grube, 2008). La mayoría de los sajales reconocidos en Xcalumkín también son acreedores de diversos cargos y títulos nominales: chak ch'ok, "gran príncipe", aj-uxul-al, "escultor", aj-h'un, "el del libro (orador)", ikaatz, "recolector de tributo", itz'aat, "sabio u hombre letrado", además de un epíteto bastante peculiar que asocia a un poderoso sajal con la Serpiente de Guerra: waxak lajun u-baah kaan, "las dieciocho cabezas de serpiente". Hasta el momento, dicha inscripción se vuelve excepcional dentro del extenso repertorio de inscripciones jeroglíficas mayas, debido a que es la única mención documentada que relaciona a un sajal con un título exclusivo de gobernantes divinos.

Las imágenes de la Serpiente de Guerra con influencia del Usumacinta detectadas en el sitio de Xcalumkín se aprecian en la Jamba 1 del Edificio de la Serie Inicial y en las Jambas 4 y 5 del Edificio Medio (en la clasificación de Graham y Von Euw, 1992), al portar allí los mandatarios retratados el tocado o casco-máscara elaborado con placas de valva, donde sobresalen los fieros dientes alineados alrededor de las fauces acompañadas por la larga lengua bífida del saurio (Figura

\footnotetext{
${ }^{1}$ David Stuart (1985) identificó este título, frecuente en las inscripciones de la región del Usumacinta, estableciendo que era utilizado por señores subsidiarios y de menor rango. No obstante, su significado preciso sigue siendo obscuro.
} 
2). Llama la atención en estos relieves la vistosa flor de lirio acuático (Nymphaea ampla) que está siendo expulsada de las fauces de la sierpe guerrera en señal de evocar la fertilidad de las cavidades de la tierra: el espacio acuoso. Otro elemento significativo, particularmente en la Jamba 5 , es la esquematización de plumas de algún ave de rapiña alrededor del tocado, que recuerda la imaginería incorporada en los cascos-máscaras de la Serpiente de Guerra de las Estelas 7 y 26 de Piedras Negras (Figura 2d, e), y que podrían corresponder a un búho rapaz (Strigidae). ${ }^{2}$ De esa forma, la serpiente y el búho fusionarían dos fuertes y temibles entidades militares: el culto a la guerra. ${ }^{3}$

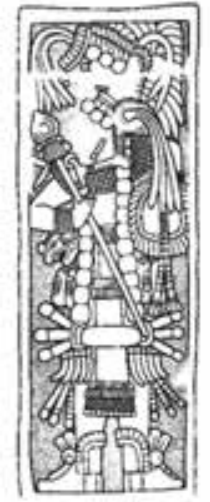

a

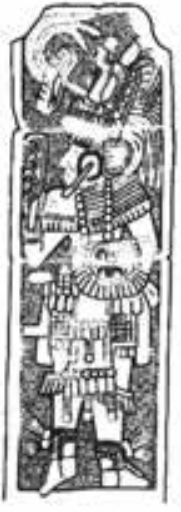

b

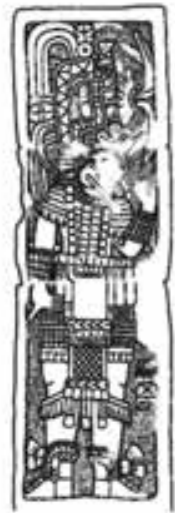

c

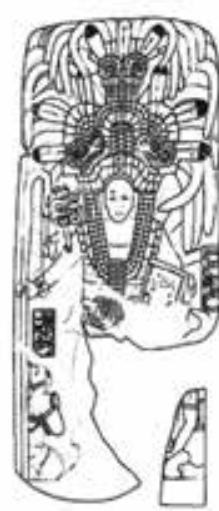

d

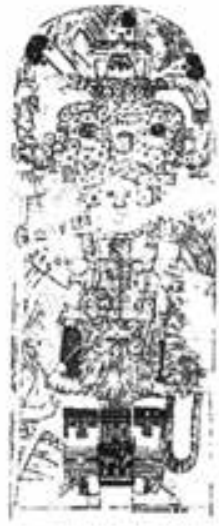

e

Figura 2. a) Jamba 1; b) Jamba 4; c) Jamba 5; d) Estela 26 PN; e) Estela 7 PN (a-c, según Graham y Von Euw, 1992; d y e, según John Montgomery [JM05430, JM05270], Copyright(C2000).

Tiempo atrás, la especialista en arte Tatiana Proskouriakoff (1950: 166) había observado en la Jamba 1 de Xcalumkín algunos elementos oriundos del Usumacinta, como el talón descubierto de las sandalias, el delantal de los taparrabos y el motivo de barbilla que representa una mandíbula inferior de serpiente, añadiendo que era similar a la representada en la Estela 3 de Bonampak. En años recientes, Julie Patrois (2008: 125), también notó la influencia iconográfica del valle del Usumacinta entre los personajes esculpidos en algunas columnas del sitio de Xcochá, como la máscara de reptil, destacando una cercanía con las Estelas 7 y 26 de Piedras Negras. En forma independiente, DesMeules y Foias (2016: 155), han puntualizado la relación entre los mandatarios representados en algunas columnas Puuc de origen desconocido, al señalar que aquellos personajes tenían relaciones directas con la dinastía real de Piedras Negras (véase Pablo, 1993).

\footnotetext{
${ }^{2}$ Familia genérica a la que pertenecen los búhos rapaces y nocturnos.

${ }^{3}$ Esta fusión puede tratarse de una reminiscencia de la deidad o criatura mitológica Búho-Lanzadardos de tradición teotihuacana (Nielsen y Helmke, 2008: 467).
} 
Siguiendo esa línea de investigación, es interesante subrayar que las Estelas 7 y 26 de Piedras Negras representan a los soberanos K'ihnich Yonal Ahk I (Gobernante 1) y K'ihnich Yonal Ahk II (Gobernante 3), ambos personajes marcadamente emparentados. El primero gobernó entre 603 y 639 y el segundo entre 687 y 729 (Teufel, 2004: 102, 143, 267; Martin y Grube, 2008: 142-145; García Juárez, 2015: 117-122). En este sentido, el lapso temporal que transcurrió entre 603 y 729 es bastante significativo; en última instancia, la regencia de K'ihnich Yonal Ahk II correspondería tentativamente al periodo en que pudo llevarse a cabo el flujo de ideas, conocimientos y posibles movimientos migratorios, entre éstos, de sajales y gente afiliada a la nobleza de Piedras Negras con dirección al noreste de Campeche.

Es probable que los sajales de Xcalumkín se mostraran públicamente, al caracterizar a la Serpiente de Guerra, como un medio de propaganda política que evocara a los Gobernantes 1 y 3 de Piedras Negras, ya que los registros escriturarios más tempranos de Xcalumkín datan del 728 y 733, fechas contemporáneas a la regencia de K'ihnich Yonal Ahk II. Por supuesto, es sólo una aproximación que no deja de resultar atractiva, pues faltaría por argumentar las condiciones (políticas o militares) necesarias para llevar a cabo un gran desplazamiento.

Por otro lado, el epíteto waxak lajun u-baah kaan, "las dieciocho cabezas de serpiente", aparece descrito en las Jambas 6 y 7 del Edificio Sur y se asocia con el sajal Kit Pa', personaje especialmente destacable dentro de la comunidad de Xcalumkín (Houston y Stuart, 1996: 299; Boot, 1996: 137; Pallán, 2009a: 32; García Nava, 2017; s/f) (Figura 3).

Sin embargo, debemos aclarar que Kit Pa' guarda también una conexión iconográfica con la Serpiente de Guerra, según lo demuestran los retratos esculpidos sobre las Jambas 6 y 7 al mostrarlo en actitud danzante y exhibir una parafernalia militar que evoca al numen marcial. El extravagante yelmo sobre su cabeza está adornado con plumas y una flor de lirio acuático; lleva dos cabezas de serpiente que mantienen las fauces entreabiertas y miran en direcciones opuestas, un mascarón en la parte central del tocado, al parecer, el dios de los meteoros pluviales, es decir, Tláloc. La cercanía y paralelismo del complejo iconográfico expuesto en el yelmo marcial de Kit Pa' sobre las jambas es idéntico, en este caso, a los empleados por algunos personajes de la élite de la isla de Jaina, al formar parte de sus atuendos de gala o de los respaldos de trono, e incluso, de la decoración a menor escala de pequeñas maquetas-templo dedicados a la Serpiente de Guerra (Figura 4). ${ }^{4}$

Asimismo, evidencia epigráfica parece corroborar los vínculos e interacción cultural a larga distancia entre la región de Piedras Negras y la zona Puuc noroc-

\footnotetext{
${ }^{4}$ De acuerdo con Karl Taube (1992), la imaginería empleada en estos ejemplares de terracota procedentes de Jaina no representa una invasión extranjera, sino una adaptación y manipulación local en la implementación de los símbolos de la Serpiente de Guerra teotihuacana.
} 


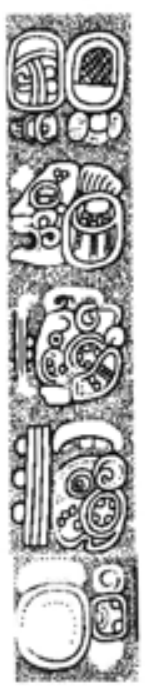

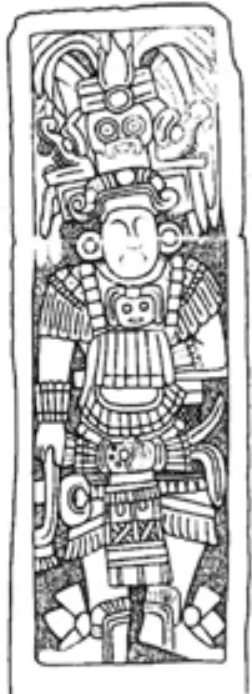

b

Figura 3. a) Detalle parcial de las inscripciones en el borde exterior de la Jamba 6 de Xcalumkín; b) Retrato del dignatario esculpido en la parte frontal de la Jamba 6 (según Graham y Von Euw, 1992; adaptación del texto jeroglífico por parte del autor).
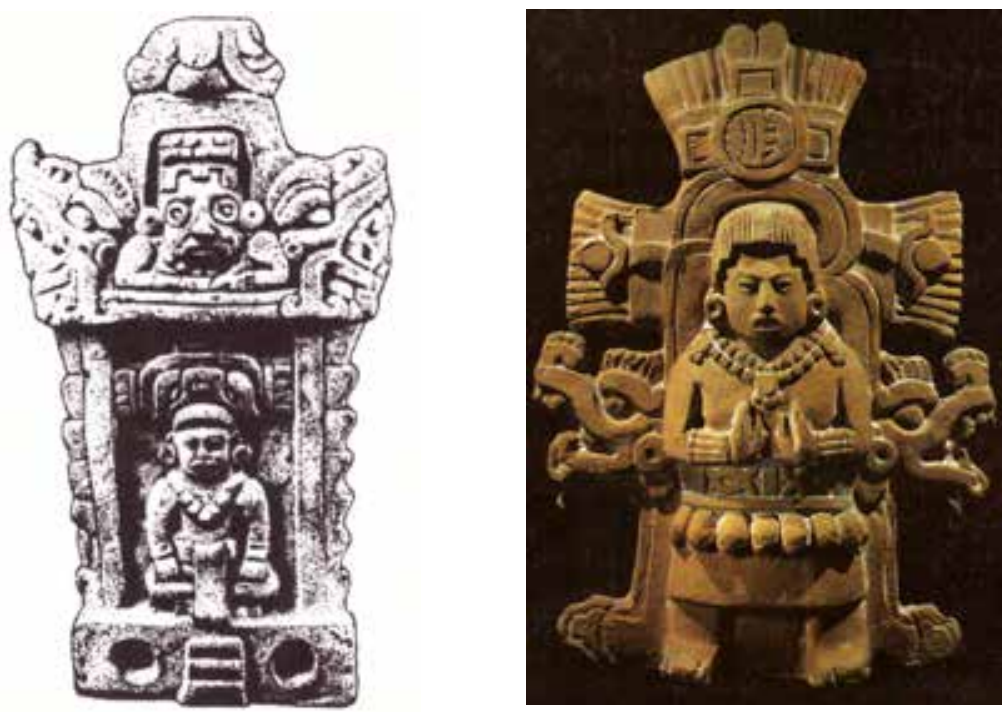

Figura 4. a) Figurilla de Jaina (según Piña Chán, 1968: lám. 21); b) Figurilla de Jaina (Fotografía Jorge Pérez de Lara, según Piña Chán, 1996: fig. 9). 
cidental en las primeras décadas del siglo octavo. El corpus jeroglífico de Xcalumkín es de los más extensos y nutridos en todo el sector noreste de Campeche (comparable con los textos de Sabana Piletas). Existen dos grupos jeroglíficos de trasfondo toponímico; el primero atestiguado en el Panel 3, con la inscripción AJk'i-K'IN-ni-a aj-k'ihn ha' o aj-k'ihn-a', cuya traducción literal es "el de Agua Caliente"; el segundo, K'IN AJAW, "Señor Solar", un título nominal que originalmente pudo haberse derivado de un glifo emblema y que se encuentra registrado en la Cornisa 1, ambas inscripciones provenientes del Edificio Sur y talladas por el mismo escultor, una estructura de estilo Puuc Temprano imbricada dentro del Grupo de los Jeroglíficos.

La inscripción AJ-k'i-K'IN-ni-a fue primeramente identificada en Xcalumkín por Carlos Pallán (2009b: 285). Dicha inscripción se atribuye a un sujeto que llevaba por nombre Pehtz' Bahlam y es a primera vista un personaje oriundo o relacionado con la región de Piedras Negras. El texto dice: yuxuul pe/h/tz'? ba/h/lam u-tel $a j-k^{\prime} i[h] n-[h] a$ ', "es el grabado de Pehtz' Bahlam, su rostro es de Agua Caliente”. Es decir, la inscripción determina el gentilicio del escultor (Figura 5a).

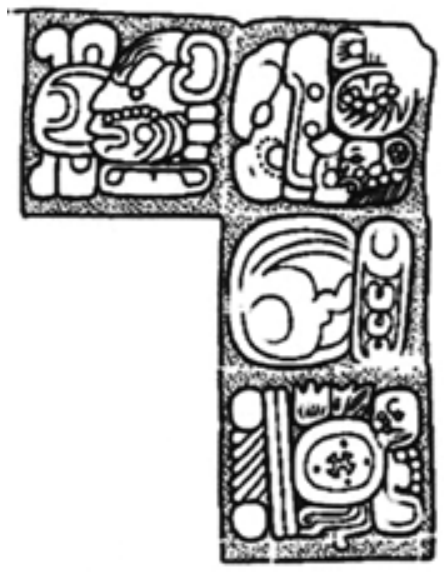

a

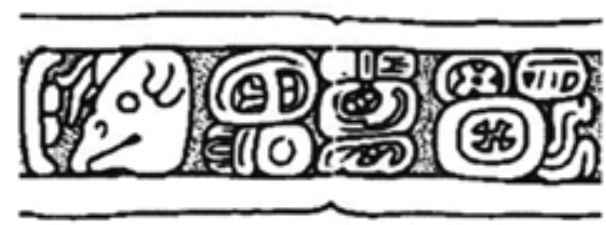

b

Figura 5. a) Panel 3; b) Detalle, Cornisa 1. Ambos textos vinculan a dos personajes posiblemente relacionados con la región de Piedras Negras (según Graham y Von Euw, 1992).

El topónimo k'ihn ha' ha sido explorado por Marc Zender (2002: 170-176), haciendo notar que fue empleado por numerosos reyes tempranos de Piedras Negras, logrando rastrear este título real por lo menos 200 años en la historia dinástica del sitio, añadiendo que k'ihn ha' tendría su origen en la capital de Piedras Negras. No obstante, Péter Bíró (2016: 141) considera que k'ihn ha' fue el nombre del Grupo Oeste de Piedras Negras. 
En el Alto Usumacinta el topónimo k'ihn ha' aparece de manera limitada en el corpus jeroglífico de la región de Piedras Negras, incluso parece no haber sido reportado hasta ahora en las inscripciones locales del antiguo reino de Yokib. Según David Stuart (2004: 2-3), k'ihn ha' no opera claramente en contextos toponímicos locales. De manera concisa ha sido detectado en inscripciones externas, en sitios como Laxtunich, la ciudad aún no identificada Sak Tz'i, los textos bélicos de Palenque, una estela de paradero inexacto (Estela de Randall) y ahora en Xcalumkín; este último se vuelve llamativamente raro y complejo por la enorme distancia entre ambas demarcaciones. Por tal motivo, es tentativo suponer que Pehtz' Bahlam, el hombre de Xcalumkín identificado con el topónimo k'ihn ha', viniese o estuviese relacionado con los alrededores de la lejana ciudad de Piedras Negras.

El otro grupo jeroglífico K'IN AJAW, "Señor Solar", forma parte del núcleo nominal de un individuo llamado Umam Kit Majan ${ }^{5}$ (Figura 5 b). Según Zender (2002: 170), k'ihn ajaw tuvo una fuerte proyección a mediados del siglo vi. Dicho término fue empleado a modo de título y no necesariamente como glifo emblema, ya que, en sitios como Piedras Negras, estos signos fueron utilizados en periodos tempranos para indicar lugares concretos o espacios donde se celebraban las ceremonias reales (Bíró, 2012: 58-59). Por esta razón, los registros k'ihn ha' y k'ihn ajaw parecen estar estrechamente coligados con la gente cortesana de Piedras Negras, de tal manera que su presencia en las inscripciones de Xcalumkín nos obliga a considerar dos disyuntivas históricas; la primera, que los personajes identificados como Umam Kit Majan y Pehtz' Bahlam, mantenían una fuerte relación con el valle del Usumacinta, y la segunda, que ambos grupos jeroglíficos aludan a topónimos regionales dentro de la zona Puuc.

\section{Columna 1 de Xcochá (ca. 728-751)}

La Columna 1 de Xcochá, también conocida como columna oeste del Edificio de la Banda Glífica, es una pieza monolítica de fuste cilíndrico con motivos antropomorfos esculpidos en bajo relieve (Figura 6). Los motivos esculpidos exhiben a dos individuos que están de pie y de perfil; el personaje de la izquierda, de mayor proporción corporal, emplea armamento marcial y porta sobre su cabeza el excéntrico yelmo de la sierpe guerrera; el segundo personaje, de dimensiones reducidas, corresponde quizás a un prisionero que ha sido amarrado por los antebrazos (Pavón, 1942: 63; Proskouriakoff, 1950: fig. 100a; Pollock, 1980: 510, fig. 856; Mayer, 1981: 22, pl. 7 right). El casco-máscara de la Serpiente de Guerra expulsa del interior de su hocico una flor estilizada de lirio acuático. En territorio

\footnotetext{
${ }^{5}$ Evidencia epigráfica alterna, proveniente del norte de la península de Yucatán, sugiere que no siempre el término u-mam, "nieto de", "abuelo de", fue empleado como cláusula de parentesco, sino que era utilizado a manera de título reverencial al añadirse al sintagma nominal (Boot, 2010: 7).
} 

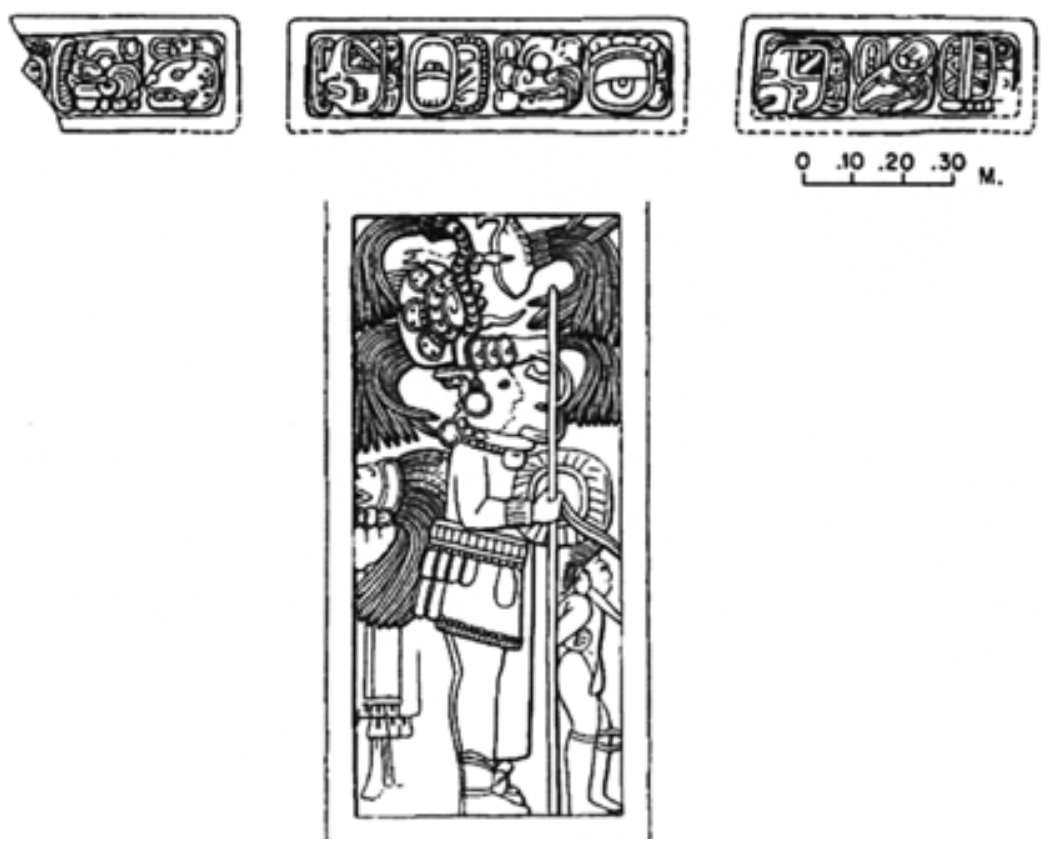

Figura 6. Capitel oriental y Columna 1 de Xcochá (según Pollock, 1980: fig. 856).

serrano, el motivo fitomorfo se asocia con la milicia y la más alta jerarquía social, y su configuración iconográfica es similar a la propaganda estilística de los sajales de Xcalumkín.

Tiempo atrás, cuando Harry Pollock (1980: 510) presenció las condiciones en que se encontraba la columna, advirtió que el capitel oeste nunca fue excavado; asimismo, precisó que la columna oriental tampoco fue recuperada porque se encontraba bastante enterrada. En la Guía del museo arqueológico, etnográfico e histórico del estado [de Campeche], publicada por el arqueólogo Raúl Pavón (1942: $63)$, se muestra desde entonces la columna oeste acompañada por el capitel este, misma que hoy en día puede verse en el Museo de Arquitectura Maya, en el Baluarte de la Soledad, en Campeche.

El capitel oriental fue esculpido en tres de sus costados con signos jeroglíficos. La lectura de las inscripciones es difícil e imprecisa pero, al parecer, el texto podría identificar a algunos de los mandatarios residentes en el ala oriental del Edificio de la Banda Glífica, o bien, gente afiliada a la oligarquía, ya que muestra de manera concisa la presencia de tres individuos con distintos antropónimos, cargos u oficios (Figura 6). El costado izquierdo, el más fragmentado, contenía tres bloques jeroglíficos, e iniciaba posiblemente con la expresión $u-k^{\prime} a b a$ ', "es su nombre", sustantivo nominal que se repite al inicio de los otros dos textos. En la cara frontal se aprecia el título itz'aat, "hombre sabio", y en el último 
costado sólo puede reconocerse con nitidez el cargo para sajal, señor subsidiario, regente o cacique; por desgracia, su antropónimo no es descifrable por el momento. En cualquier caso, el personaje principal de la Columna 1 puede ser identificado como un sajal. La desconocida columna este, de igual forma, es casi seguro que haya contenido un personaje con características similares. Por ejemplo, Karl Mayer (2012: 2) ha propuesto que la Columna 1 de Santa Ana y el fragmento superior de una columna de procedencia desconocida mantienen bastantes similitudes iconográficas, proponiendo que no sólo provienen de un sitio arqueológico común, sino que también proceden de una única estructura dentro de la zona Puuc. También es buen ejemplo el par de columnas norte y sur originarias de la Estructura D6-15 de Xculoc (ver Figura 8) y las columnas de las portadas del Edificio 4B1 de Sayil que, junto con las Columnas 5 y 6 de Xchan, ofrecen ciertas semejanzas escultóricas de manera simultánea y paralela (Proskouriakoff, 1950: fig. 101; Pollock, 1980: fig. 269; Gendrop, 1983: 156-157; Novelo y Benavides, 2018). A todo esto, debe señalarse —según nuestras observaciones-que algunos recintos arquitectónicos de tradición Puuc Temprano de la región de Xcalumkín y sus alrededores, contienen columnas esculpidas en la fachada principal con motivos iconográficos casi simétricos, algunos ejemplares con grabados jeroglíficos y otras veces con los retratos de los señores principales que ocuparon o visitaron periódicamente los edificios de poder.

En cuanto a la datación de la Columna 1 de Xcochá, el Edificio de la Banda Glífica presenta elementos decorativos propios de la fase Puuc Temprano (Andrews, 1986: 31), a pesar de que en dicha estructura se pueden observar rasgos constructivos de estilo Proto Puuc (Pollock, 1980: 585). Por su parte, Proskouriakoff (1950: 167, 197) y Pablo (1993: 243) argumentan que el estilo icónico pertenecía a la Calidad X, correlativo al periodo Clásico Tardío. De tal manera que la columna puede fecharse entre los años 728 y 751 de nuestra era, en razón de que las columnas y capiteles esculpidos aparecen en este horizonte. Además, el registro epigráfico con el cargo-oficio para sajal era inexistente en la región hasta su inserción plenamente documentada hacia 728 y 731.

En resumen, el personaje de la Columna 1 de Xcochá puede identificarse con firmeza con un sajal que viste claramente la indumentaria de la llamada Serpiente de Guerra. Las inscripciones del capitel oriental guardan una semejanza sintáctica y gramatical con los textos del Dintel 1 del Edificio de la Serie Inicial y la Cornisa 1 del Edificio Sur de Xcalumkín, al ofrecer un listado de los personajes que transitaban al interior de las edificaciones; igualmente, se tiene conocimiento de sus antropónimos, cargos y epítetos (García Nava, 2017).

\section{Sierpes de Guerra en Itzimté Bolonchén (ca. 731-910)}

El arqueólogo norteamericano Eric Von Euw (1977) dirigió el corpus jeroglífico en el sitio de Itzimté, municipio de Bolonchén, Campeche. En el censo levantado, 
las Estelas 1 y 7 mantienen un fuerte paralelismo simbólico, y entre los relieves visibles logramos identificar elementos significativos para proponer que el/los dirigentes retratados estaban caracterizando a la Serpiente de Guerra, conclusión a la que había llegado con anterioridad Jeff Kowalski (1994: 110). Por desgracia, la Estela 1 muestra un severo deterioro, además de encontrarse fragmentada (Figura 7a).

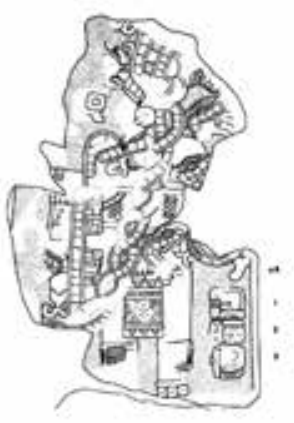

a

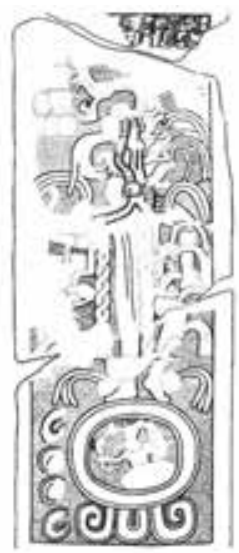

b

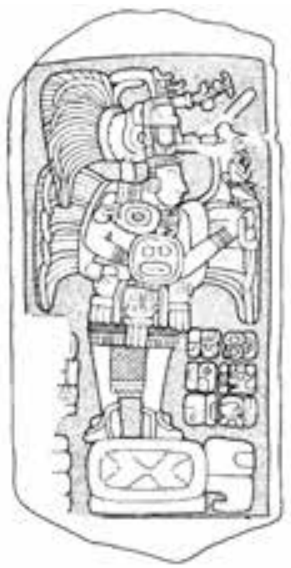

C

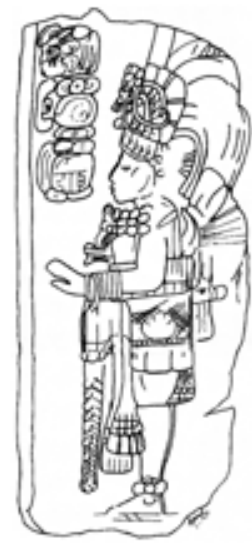

e

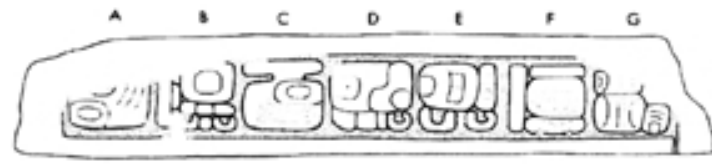

d
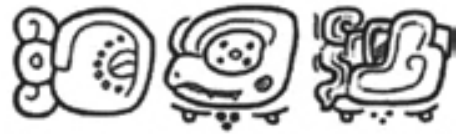

f

Figura 7. a) Detalle de la Estela 1; b) Detalle de la Estela 7; c) Dintel 1; d) Inscripción del borde frontal del Dintel 1 (a-d, según Von Euw, 1977); e) Dintel 2 (Dibujo: Azael García); f) Detalle del texto de una vasija de estilo Chocholá (según Zender, 2010: fig. 9).

No obstante, entre los motivos iconográficos que han logrado preservarse en la Estela 1 se observa a un mandatario de pie con la cabeza orientada al costado derecho, que porta el icónico casco-máscara de la Serpiente de Guerra. Se distinguen tres cabezas pequeñas de víboras en la parte posterior del yelmo, una rodela que era sostenida por la mano izquierda y una imponente cuerda entrelazada que parece surgir de la parte posterior de la mandíbula del casco-máscara, como si se tratara del cuerpo de la entidad ofidia. En la zona abdominal del dignatario también es posible reconocer motivos entretejidos; en contexto calendárico, dichos diseños se encuentran infijos en el signo Pohp (k'anjalaw o k'anjalaab, primer mes de la veintena del Haab) y a menudo se traducen como "estera". Este signo denota autoridad, gobierno y condición social. En el sistema escriturario recibe el 
valor jal, "tejido", refiriéndose exclusivamente al tipo de material empleado en la elaboración de la vestimenta (Stone y Zender, 2011: 81). En el flanco derecho, a la altura de las piernas, persisten tres cartuchos jeroglíficos: $y$-uxul-il? bahkab wak tuun, "el grabado del primero en la tierra, 6-Tuun".

En cambio, la Estela 7 se conserva en mejores condiciones y sus inscripciones han sido objeto de un estudio muy reciente (Figura 7b). De acuerdo con GrañaBehrens (2002: 303; 2016: 170-172), los textos en piedra del sitio de Itzimté pueden fecharse entre los años 731 y 910 . En cuanto a la pieza monolítica en discusión, asienta que el monumento pétreo data del año 751 d.C. tomando como referencia principal el enorme cartucho jeroglífico con la anotación 2 Ajaw esculpido en el registro basal de la estela, sobre el cual está bailando el mandatario en turno; asimismo, el autor apunta que las Estelas 1 y 7 pueden ser resultado del mismo proyecto constructivo implementado por el Gobernante 1-2, siendo posible que en la antiguiedad llevara por nombre K'ak o Mihinil K'inich Ch'ok Pitz.

En este trabajo se pretende destacar una vez más que los sujetos retratados en las Estelas 1 y 7 (Gobernante 1-2), personifican a la Serpiente de Guerra. A diferencia de la estela anterior, el número 7 exhibe la cabeza de una gigantesca serpiente en actitud ofensiva justo por encima del casco-máscara y la cuerda entrelazada, que se asocia con los mandatarios; en esta ocasión combina serpientes que miran en direcciones opuestas, formando así un largo ornamento que cuelga alrededor de su cuello.

Otro monumento pétreo por destacar es el Dintel 1 (Figura 7c). La escena muestra a un personaje ricamente ataviado con plumas que formaban parte del tocado y del perchero colocado detrás de la espalda, la efigie central del yelmo corresponde al Dios K'awiil; además, se observa que empuña con la mano izquierda el pie serpentino del cetro-maniquí de la misma deidad. Es evidente que el mandatario se encuentra parado sobre un cartucho toponímico de gran tamaño. Según Carlos Pallán (2009b: 287) este signo se encuentra a medio camino entre lo icónico y lo escriturario, presentándose así la secuencia para el virtual título K'IN-ni-wa. Por lo tanto, la transliteración está prescrita bajo la forma K'IN-ni["AJAW]-wa, "Señor Solar", haciendo alusión nuevamente al título emblema de posible origen extranjero; pero, por otra parte, no sabemos si estamos frente a un topónimo local. ${ }^{6}$

A pesar de que el registro jeroglífico de esta región es limitado, debe resaltarse que el término k'ihn ajaw puede vincularse con un lejano lugar de origen o título emblema utilizado como vía de legitimación y jerarquización social. La movilidad de epítetos y el flujo de ideas parecen haber rendido frutos en Xcalumkín; igualmente, el sitio de Itzimté no sería la excepción.

\footnotetext{
${ }^{6}$ La iconografía de algunas estelas del sitio de Machaquilá, Guatemala, representan un buen ejemplo para despejar algunas interrogantes. Las Estelas 4, 7, 8, 10, 18 y 19 contienen en su registro basal representaciones de cuadrilobulados que han sido asociados con cuerpos de agua; dichos espacios se encuentran recreados de manera física dentro de la Plaza A (Lacadena, 2006: 78-80).
} 
Los jeroglíficos que aún se conservan en el costado derecho del cartucho toponímico indican solamente la dedicación del grabado, siendo más llamativo el texto inscrito en el borde frontal del mismo monumento, que resulta inusual por su rareza en el corpus jeroglífico serrano. Las primeras anotaciones son confusas, pero los grabados posteriores (E-G) muestran otro topónimo de tintes mitológicos: u-ti-ya NAH-HO'-CHAN-na bo-bo-?, "sucedió en Nah Ho' Chan Bob...?" (Figura 7d). El lugar Nah Ho' Chan fue comentado previamente por Stuart y Houston (1994: 71), donde señalaron que aquella inscripción servía de epíteto para los Dioses Remeros (Paddler Gods) dentro de una geografía mítica. Un espacio liminar que ha sido vinculado por Erik Velásquez (2010: 117) con una zona oscura al interior de una montaña, un sitio de sacrificio y nacimiento en el que converge la vida y la muerte del Dios del Maíz. Por otra parte, Źrałka y colaboradores (2018: 19) observaron que el sujeto principal mencionado en la Estela 1 de Nakum se consideró asimismo como perteneciente o afín a esta localidad sobrenatural; igualmente, han agregado que varios individuos históricos de Tikal y Naj Tunich incluyeron este topónimo en su cuerda titular. Este puede ser el caso del personaje del Dintel 1, que presumiblemente reclamaba autoridad y legitimidad al refrendar sus lazos de identidad a través de estos espacios de naturaleza sagrada.

En lo que toca a la transcripción bob, "flor", es importante precisar que en lenguas yukatekanas bob o b'oob' significa "flor de henequén" o "tallos largos como largas cañas, que echa el maguey” (Barrera Vásquez, 1980: 58; Arzápalo, 1995: 88; Bricker, Po'ot y Dzul, 1998: 33), y en la misma línea semántica, bob en idioma ch'ol es "flor" o "flor de plátano" (Aulie y Aulie, 1978: 32; ver Lacadena y Wichmann, 2004: 139). De igual forma, resulta interesante conocer que el vocablo tzeltal boc nichte quiere decir "azucenas de la tierra" (Ara, 1986: 251). De estar en lo correcto, el aspecto floral, húmedo y perfumado de Nah Ho' Chan sería el apropiado para un lugar de transición entre la vida y la muerte; un sitio divino que garantizaría la continuidad dinástica de los antiguos soberanos mayas. A todo esto, el jeroglífico erosionado de la última inscripción pudo haber estado acompañado por un sufijo locativo -nal. En Itzimté, la mítica región Nah Ho' Chan Bob... puede ser parafraseada de la siguiente manera: "el Lugar Florido es el Primer Cinco Cielo".

Finalmente, el Dintel 2, recuperado en la zona arqueológica de Itzimté, en el costado suroeste de la Estructura 59 (Mayer, 1999: 95), destaca por el personaje esculpido y el texto que lo acompaña (Figura 7e). La pieza monolítica no contiene (o no se conservaron) anotaciones calendáricas inscritas, pero ha sido fechado tentativamente hacía 849 (Graña-Behrens, 2016: 184-185). El monumento fue esculpido en bajo relieve y muestra a un sujeto de perfil, que evidentemente presenta una parafernalia de alto rango: el elemento principal consiste en el casco-máscara de la Serpiente de Guerra que cubre la cabeza del dignatario; se observan copiosas y largas plumas que formaban parte del mismo atuendo. El personaje del Dintel 2 también está desprovisto de la flor de lirio acuático, insignia tan arraigada en el arte en piedra de los sajales de Xcalumkín y Xcochá. Asimismo, viste un collar de numerosas cuentas de algún tipo de piedra semipreciosa y sobre la espalda 
carga un perchero. La mano izquierda parecía sostener una efigie; en la misma extremidad un largo cordel entrelazado junto con una cinta cubre el antebrazo, evidenciando el contenido ritual de la escena. En Palenque, el evento de "toma de soga" se asocia a rituales que anteceden a la entronización de jóvenes principales que se convierten en futuros gobernantes (Stuart, 2005: 44).

Una corta inscripción se conserva en la parte superior izquierda; contiene tres bloques jeroglíficos dispuestos en línea vertical (ver Grube en Mayer, 1999: 94; Graña-Behrens, 2016: 177-178; 2018: 174) y su morfología indica lo siguiente: XOOK u-yu-ku-li K'UH-?-AJAW-wa. El primer signo al parecer trata del sustantivo xook con significado literal para "tiburón". Enseguida se observa una inscripción con lecturas variables: $u$-yuk-il o tal vez $u$-yuk-[b]il? donde consideramos algunos argumentos para el escudriñamiento de la expresión. Años atrás, Marc Zender (2010: 10-12) demostró que yuk o yuhk, "sacudir", forma parte de un grupo de verbos afectivos o reiterativos. ${ }^{7}$ Asimismo, detectó la forma $y u k$-bil en un texto inscrito sobre una vasija estilo Chocholá, proponiendo que lenguas como el itzaj contienen el sufijo cognado -bil formando así un participio pasivo en las raíces CVC; por lo tanto, yuk-bil es complementaria a las formas afectivas (Figura 7f).

Sin embargo, la presencia del signo $u$ - indicaría alternativamente que $y u k$ se comporta como un sustantivo al estar prefijado por un grafema de tercera persona del singular, y el sufijo -il solamente es una marca de sentido abstracto. De hecho, existe evidencia que demuestra su acepción como sustantivo para "agitación, sacudida, temblor o terremoto", principalmente en lenguas ch'ol, chortí, yukateko y mopán (Ulrich y Ulrich, 1976: 254; Barrera Vásquez, 1980: 981; Kaufman, 2003: 1286; Sosa et al. 2003: 130; Zender, 2010: Table 3; Esparza y Velásquez, 2013: Table 1). Por lo tanto, la evidencia apunta hacia otra directriz, en este caso la expresión puede referirse al antropónimo del sujeto como $u$-yukil- $\emptyset$ "es agitador", "es sacudidor". La parte final del texto contiene la expresión $k^{\prime} u h[u l] . . . ?$ ajaw, "Divino Señor...". ${ }^{8}$ En concreto, el texto refiere exclusivamente al nombre del personaje esculpido en el Dintel 2 y puede ser leído parcialmente como xook u-yuk-il k'uhul... ajaw, "Tiburón Sacudidor es el Divino Señor de...".

De acuerdo con los datos presentados, la inscripción del Dintel 2 muestra indicios de lenguas vernáculas del tronco yukatekano y ch'olano. Los datos presentados, a pesar de ser insuficientes, demuestran buena evidencia y vienen a dar luz sobre el origen o vínculos idiosincráticos de algunos mandatarios de Itzimté de los siglos vill y Ix. Por ahora, es llamativamente raro que en este sitio abunden las estelas, a diferencia de otros sitios periféricos; ello quizá demuestra también lejanos vínculos e influencias con las Tierras Bajas del sur. ${ }^{9}$

\footnotetext{
${ }^{7}$ Ver Stuart, 2001; Velásquez y Esparza, 2013; Esparza y Velásquez, 2013.

${ }^{8}$ Graña-Behrens (2016: 180-181, 2018: Table I) es de la opinión de que el prefijo y el signo principal de la posición A3 del Dintel 2 corresponden a la forma i-T709-AJAW.

${ }^{9}$ En Xcalumkín se encontró un bloque de piedra esculpido con características similares a una estela, que contiene una espiga para empotrarla y mantenerla enhiesta (Michelet et al., 2007; García Nava, 2018: 22).
} 


\section{La Estructura D6-15 de Xculoc: culto al Dios del Maíz-Cacao (ca. 730-771)}

En la región de Xculoc se encuentran otros sitios que guardan una considerable cercanía, entre ellos Xcochkax y Chunhuhub. La ocupación de estos asentamientos fue bastante corta, y en el caso de Xculoc y Xcochkax hay fuertes indicios que apuntan a una breve ocupación que oscila entre la fase Puuc Temprano y Puuc Clásico; es decir, entre 730 y 1000 d.C. (Michelet y Arnauld, 2006: 78). En cuanto a la culminación del sistema escriturario, la datación es más corta para esta elongación regional de la zona Puuc Noroccidental, las fechas discurren entre los años 720 y 770 (García Campillo, 1995: 273-274).

En Xculoc, la Estructura D6-15 o Edificio de las Columnas Labradas está considerada como la principal edificación de estilo Puuc Temprano. Antiguamente contaba con tres cuartos dispuestos en línea recta, el central difiere de los otros, ya que su acceso principal estaba constituido por dos columnas esculpidas ${ }^{10}$ (Pollock, 1980: 379; Michelet y Becquelin, 1995: 123; Becquelin, 2002: 121). Los estudios epigráficos e iconográficos de los relieves esculpidos sobre los diversos soportes arquitectónicos que decoran la fachada del inmueble son escasos, o bien, insuficientes (Pavón, 1942: 44, 46; Pollock, 1980: 379; Mayer, 1981: 23; Gendrop, 1983: 156; García Campillo, 1995: 174-176; Grube, 2003: 352; Patrois, 2008: 148, 211). No obstante, en este ensayo pretendemos mostrar una nueva interpretación del contenido simbólico a partir del lenguaje visual ejecutado en la plástica del recinto, permitiéndonos identificar un mundo coligado a la tierra, el inframundo y la materia orgánica vegetal, pues creemos que el salón central era el hogar del Dios del Maíz-Cacao.

La fachada principal del salón central de D6-15 poseía antaño tres accesos, segmentados por dos columnas no monolíticas, constituidas por dos sillares (Figura 8). Entre los elementos iconográficos a destacar en la imaginería de los mayas de Xculoc se encuentra, al parecer, el mito de renacimiento del Dios del Maíz que abunda en distintas ciudades de las Tierras Bajas del sur. Sin embargo, es llamativamente raro encontrar en estas latitudes una estructura de estilo Puuc Temprano con una fuerte carga simbólica y estética destinada a las concepciones religiosas: el señor principal personificando al Dios del Maíz fusionado con el Dios K'awiil, un numen de contrastes políticos, agrícolas y pluviales.

Los bajorrelieves de las columnas norte y sur muestran el retrato frontal de un individuo de pie ricamente ornamentado posado encima de un mascarón sobrenatural. Al parecer ambas columnas son idénticas y exhiben al mismo personaje; lamentablemente, el tiempo y la intemperie han erosionado los diseños. Entre

10 De acuerdo con Proskouriakoff (1950: 168) los dinteles de D6-15 fueron reutilizados en esta estructura y fueron tallados antes que las columnas. Por su parte, Pollock (1980: 382) llamó la atención al señalar que la fachada principal de D6-15, inicialmente segmentada por dos columnas y tres claros, fue modificada con posteridad, anulándose los cuartos laterales y recubriendo con estuco los relieves de las columnas. 

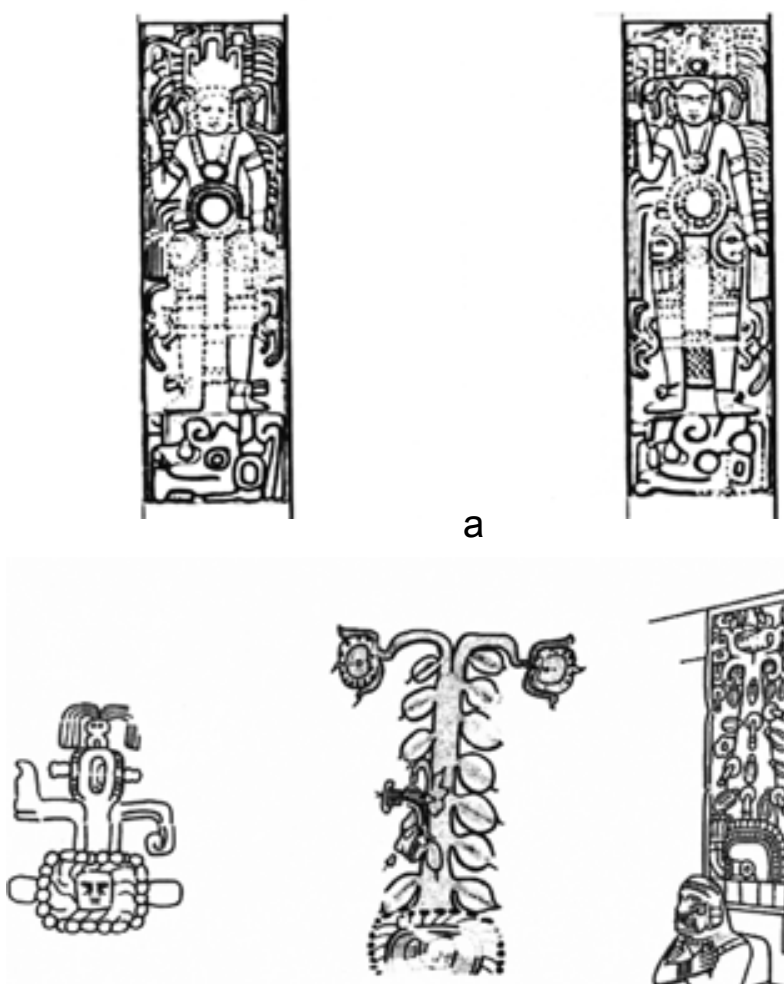

b

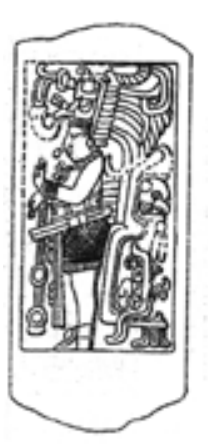

a

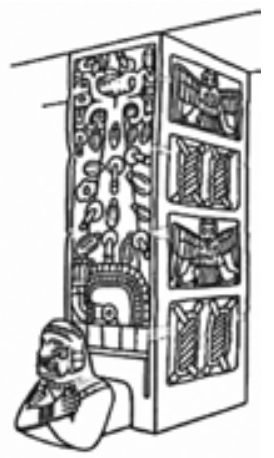

d

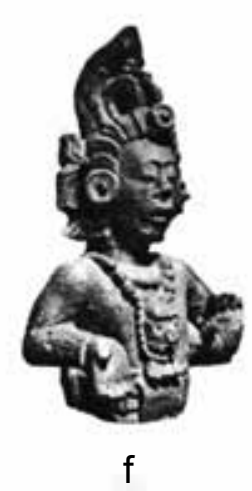

Figura 8. a) Columnas norte y sur de la Estructura D6-15 de Xculoc (según Pollock, 1980: figs. 629630); b) Detalle de la Estructura 1B-2 de Quiriguá (según Looper, 2003: fig. 2.15); c) Detalle K5615; d) Pilastra Oeste del Templo de los Búhos, Chichén Itzá (c y d según Martin, 2006: figs. 8.7 y 8.15);

e) Dinteles Norte, Centro y Sur de la Estructura D6-15, Xculoc (según Pollock, 1980: fig. 632);

f) Busto del Dios del Maíz procedente de la Estructura 22 de Copán (según Thompson, 1965). 
los elementos perceptibles, salta a la vista el enorme arreglo de plumas del personaje, a pesar de que el motivo central del yelmo no es reconocible. Utiliza joyería de piedras semipreciosas sobre el cuello y orejas, hace uso de brazaletes y muñequeras; parece empuñar con la mano derecha un excéntrico de piedra. En los costados de la cabeza, por encima de las orejas y a la altura de las rodillas emerge vegetación, específicamente en las extremidades inferiores se muestra de perfil la baya del lirio acuático. En la columna sur, se observa un faldellín de redecillas que recuerdan uno de los atributos del Dios del Maíz y de los númenes lunares, aunque en la zona del vientre presenta una especie de espejo o rodela que, en este contexto, podemos identificar con una flor. ${ }^{11}$

Matthew G. Looper (2003: 66-68) argumenta que estos diseños corresponden a la personificación de las montañas, motivos de flores de las que emergen foliaciones de maíz; por su parte, Karl Taube (2004: 81-82) señala que representan la Montaña Florida, un lugar que evoca la vivienda de los ancestros y, en algunas situaciones, es el punto de contacto entre las aguas del inframundo y el cielo, un axis mundi. Por lo tanto, la iconografía que nos ocupa puede ser un ejemplo más del árbol cósmico representado por el señor principal de la Estructura D6-15 al caracterizar al Dios del Maíz (Figura 8b).

Asimismo, sabemos que existe en el extenso repertorio iconográfico maya, con fuertes analogías de connotaciones simbólicas entre la relación Dios del Maíz-Cacao y cocodrilo-cacao (Barrera Vásquez, 1976; López Austin y López Luján, 2009: 291; Martin, 2006: 163-169; 2012: 112-113; Miller y Martin, 2004: 62-63; Taube, 2005: 25). El motivo floral que adorna la zona ventral de los personajes de Xculoc aparece en otras fuentes donde es ilustrado el Dios del Maíz como un prodigioso árbol de cacao. Un vaso policromo de contexto desconocido fechado para el Clásico Tardío ofrece un panorama visual significativo al ubicar el motivo floral en la base del árbol de cacao; claramente la cabeza del numen es una vaina para elaborar el preciado chocolate (Figura 8c) (Martin, 2006: 165; 2012: 114; Wagner, 2000: 35-36). Escenas análogas, con acentuada similitud a la flor de Xculoc, se ubican en la Pilastra Oeste del Templo de los Búhos en Chichén Itzá, del Clásico Terminal (Figura 8d). La imagen exhibe a un joven Dios del Maíz en actitud dinámica, un contorsionista con los brazos cruzados; este tipo de representaciones en realidad aluden al crecimiento y representación del Dios del Maíz como árbol de cacao o la bien conocida Ceiba pentandra (Taube, 2005: 25).

\footnotetext{
${ }^{11}$ Existe un gran paralelismo entre el motivo de la flor y los espejos que sujetan entre las manos y a la altura del vientre algunas esculturas monumentales que visten el tocado de la Serpiente de Guerra teotihuacano, la mayoría procedentes del altiplano central mexicano; sin embargo, estos espejos circulares también pueden identificarse con las flores, pétalos y mariposas (Taube, 1992: 78-79; 2016: 304). Asimismo, Proskouriakoff (1950: 168) notó el diseño de disco entre las columnas de Xculoc y la relación con algunas columnas de Oxkintok. Por otra parte, este diseño mantiene cierta similitud con los seis elementos decorativos que flanquean la Portada Jeroglífica del Edificio 35 de Sisilá, que prácticamente son iguales a los reportados en sitios como Edzná, Xkichmook y Kabah durante el Clásico Terminal e inicios del Posclásico y se identifican con rodelas que denotan un aspecto bélico (Benavides, Novelo y Pallán, 2011).
} 
El ejemplar de Chichén Itzá deja en claro su conexión con el árbol florido; del cuerpo del numen agrario emerge el árbol de cacao que está embellecido por joyas y piedras semipreciosas; en el interior de la flor se observa un cráneo humano, tal parece que expulsa de la boca descarnada el hálito de vida, por lo que podemos dilucidar que la flor es sinónimo de la montaña, de culto a los ancestros; es lugar de muerte y renacimiento en un espacio acuoso que gesta periódicamente al joven Dios del Maíz, una geografía sagrada semejante a Nah Ho' Chan Bob. El icono de flor puede interpretarse en Xculoc como un elemento pars pro toto que define implícitamente a las vainas de cacao aunque no estén visibles; la flor determina su presencia; en otras palabras, las columnas norte y sur evocan también al árbol de cacao por medio del signo floral. Por tal razón, la imaginería expuesta en la iconografía de Xculoc es claramente una metáfora en torno al mito del renacimiento del Dios del Maíz-Cacao; el árbol florido es propiamente el señor principal regente del edificio. ${ }^{12}$

De regreso a los elementos icónicos visibles en las columnas, nuevamente en ambos pilares se observa en el registro basal un mascarón de aspecto grotesco que está orientado de perfil hacia el flanco derecho. La criatura corresponde al Dios K'awiil, distinguible por la antorcha humeante que emerge de su frente y su largo labio superior que se pronuncia ligeramente hacia arriba; en este contexto la entidad figura la tierra y/o montaña (Gendrop, 1983: 156; Patrois, 2008: 148).

De hecho, el contenido simbólico de los dinteles norte, centro y sur de la Estructura D6-15 muestran una serie de retratos que identificamos una vez más con el joven Dios del Maíz (Figura 8e). En los tres relieves es clara la presencia del motivo de antorcha que emerge de los diferentes yelmos de K'awiil; sin embargo, el dintel central puede incluso representar a Tláloc, dios de los meteoros pluviales. El dintel norte ofrece un panorama más transparente en cuanto a la identificación de la deidad: su cabello bien recortado, el faldellín de bandas cruzadas o redecilla, el perchero en la espalda (back rack) y el dinamismo con que gesticula las manos son elementos pertenecientes al Dios del Maíz del periodo Clásico (Figura 8f).

Por otra parte, los erosionados y confusos jeroglíficos de los bordes de los dinteles impiden efectuar una lectura razonable de las inscripciones, pues no existe ningún trabajo de análisis riguroso en alcance al desciframiento de los signos, a pesar de que el corpus de inscripciones de Xculoc es bastante limitado. Comentarios efectuados por Nikolai Grube al leer parcialmente una cláusula tipo fórmula dedicatoria del dintel central señalan que los textos sobre las ménsulas de los capiteles de ambas columnas están decorados con glifos falsos (Grube en Michelet y Becquelin, 1995: 123; Grube, 2003: 352). También se suma a los

\footnotetext{
${ }^{12}$ Quizás existe alguna remota relación con el lugar mítico de Tamoanchan de tradición nahua, donde el árbol cósmico al partirse sangra tejos de oro y cuentas de jade: es el principio, el movimiento, el tiempo, el espacio, el equilibrio cósmico, casa de dioses e incluso un paraíso terrenal (López Austin, 1994: 72-73; López Austin y López Luján, 2009: 169; Stone y Zender, 2011: 213).
} 
esfuerzos epigráficos García Campillo (1995: 174-175) con su trabajo doctoral, al ofrecer lecturas tentativas para el desciframiento de posibles títulos nominales, aunque por el momento no se ha identificado el antropónimo del señor principal de la Estructura D6-15. No obstante, seguimos elaborando propuestas y teorías a base del gran registro técnico, documental y fotográfico propiciado por Harry D. Pollock (1980).

A pesar de la poca atención prestada, las inscripciones esculpidas en el borde posterior del dintel central aportan otra referencia en torno al hábitat del Dios del Maíz. La lectura confirma que el edificio llevaba por nombre un topónimo bien conocido en el registro escriturario del Clásico Temprano y Tardío. Los jeroglíficos se esculpieron en escritura en espejo y se leen de derecha a izquierda: yu-xu-lu-li u-k'a-li 7-CHIT K'AN-na-[*NAL], "es el grabado en el recinto del Lugar del Siete... Precioso". ${ }^{13}$ El signo T580 o CHIT permanece aún sin ser descifrado, desconociéndose su etimología, y su presencia en el corpus jeroglífico se acentúa en contextos de autosacrificio, ayuno o penitencia. De igual forma, el dintel norte, en su inscripción frontal, determina otra mención bastante similar a la anterior: 7-CHIT-na K'AN-na ${ }^{14}$ (Figura 9a). Ocasionalmente, dicha anotación jeroglífica aparece en las inscripciones de manera pareada con otro topónimo de lectura incierta conocido como 9-HUL?-T629, mismo que se encuentra estrechamente conectado al inframundo.

En el caso concreto del dintel central, Wuk Chit K'an Nal es claramente una localidad mitológica asociada con la apoteosis del Dios del Maíz. Este topónimo designa la grieta de la montaña por la cual germina el maíz (Tokovinine, 2012: 127); además, este glifo se relaciona rotundamente con los ancestros, el renacimiento después de la muerte, el crecimiento del maíz tierno y el nacimiento del sol por el oriente (Stuart, 2009: 323-324). Dentro de la imaginería de los antiguos mayas queda claro el vínculo establecido entre el Dios K’awiil y el topónimo Wuk Chit K'an Nal. Una caja cerámica fechada para el Clásico Temprano muestra el retrato de perfil del Dios K'awiil presentando u ofrendando el signo toponímico en cuestión. De esta manera, podemos señalar que K’awiil era la entidad patrona o regente de este lugar sagrado donde se transfigura el cuerpo del Dios del Maíz por uno fuerte y jovial (Figura 9b). En el sitio de Xculoc, la fórmula Dios del Maíz-Wuk Chit K’an Nal-K'awiil forma parte integral de un complejo y excéntrico palacio de estilo Puuc Temprano.

\footnotetext{
${ }^{13}$ Este topónimo entra en extrapolación con otros jeroglíficos que se asemejan a la forma wuk chit k'an nal, como wuk k'an nal, "Lugar del Siete Precioso" (K4340) y wuk ha' nal, "Lugar de Siete Agua[s]" (ver K1202, K3500 y un plato estilo códice de procedencia desconocida del Denver Art Museum). Este último destaca por ser una región acuosa en la que se sumerge o "entra al agua" la deidad jun ixiim ahiin, "Uno Maíz Cocodrilo" (ver K6979). En general, los tres topónimos mitológicos forman parte de algún estrato, casa o región del inframundo, donde el Dios del Maíz transita periódicamente para abrirse paso a una futura resurrección.

${ }^{14}$ Erik Boot (2009: 70) ya había observado el fenómeno escriturario T580-na, agregando que, en este caso, puede tratarse del sustantivo que designaba el nombre propio del Edificio de las Columnas Labradas de Xculoc, o bien, que el signo -na era una versión completa del signo principal T580.
} 

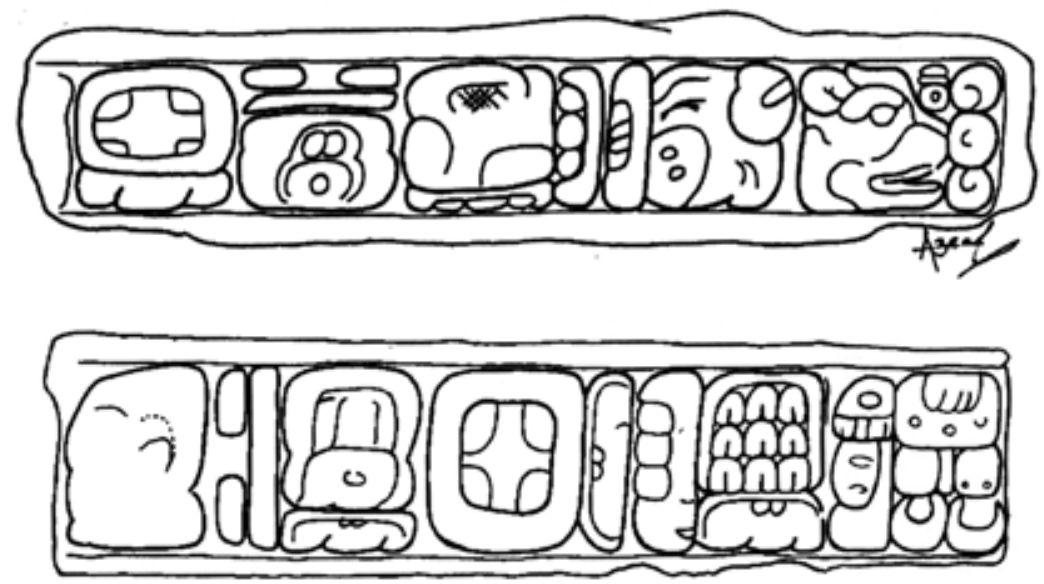

a
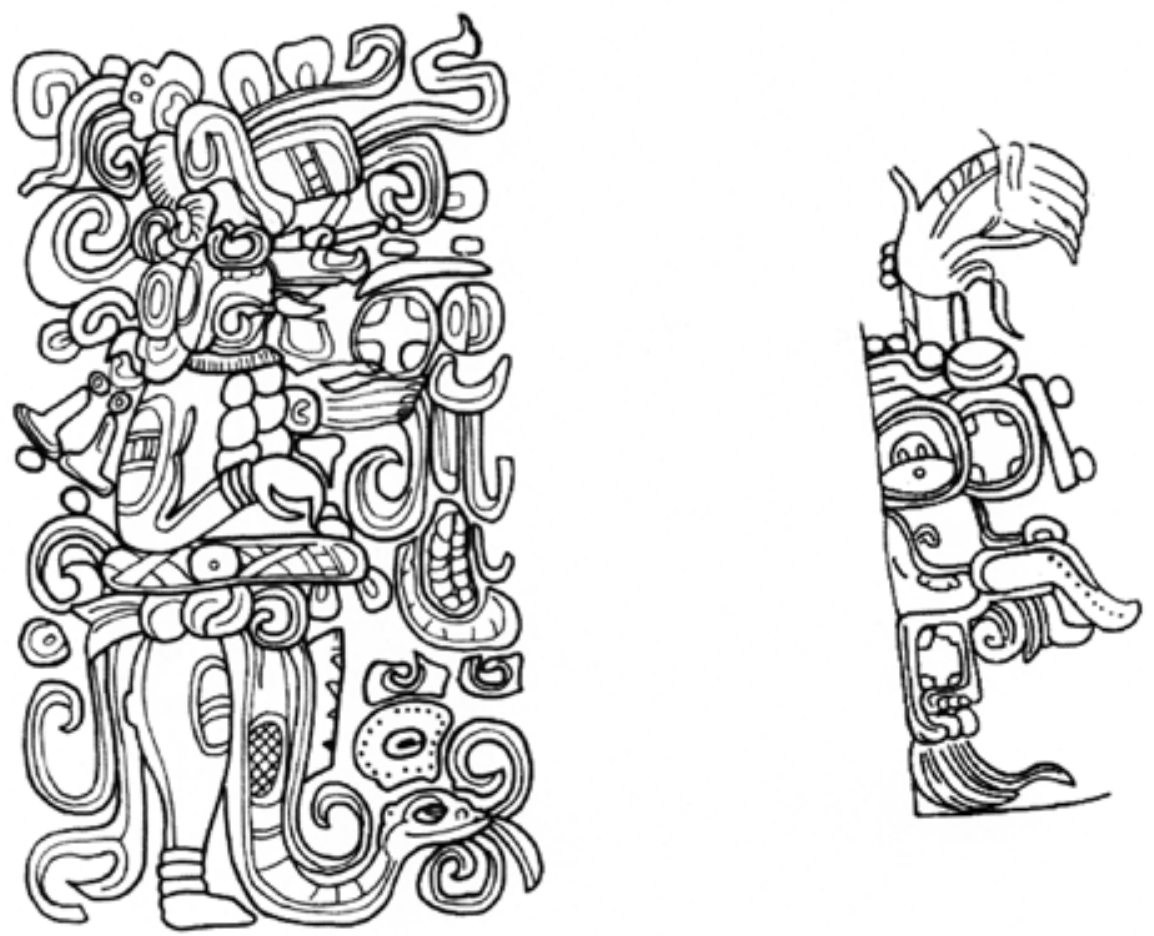

b

C

Figura 9. a: Dintel central y dintel norte; b: Detalle, K3801;

c: Detalle de la Columna 5 de Xchan (Dibujos: Azael García). 
En estas latitudes, la singular toponimia está presente en la Estela 3 de Tzum y en una bella vasija de ónix atribuida a la ciudad portuaria de Jaina. Recientemente, la localidad mitológica ha sido detectada por Sara Novelo y Antonio Benavides (2018) en los motivos que decoran el extremo inferior de las Columnas 5 y 6 del Grupo Danzantes de Xchan; en ambas columnas, una criatura semejante al Monstruo del Lirio Acuático lleva por atuendo la compleja inscripción (Figura 9c).

En suma, el contenido simbólico de los relieves esculpidos en las columnas y dinteles de D6-15 está dedicado al mito de renacimiento del Dios del MaízCacao. El edificio era visualizado como la personificación animada del Wuk Chit K'an Nal, un espacio húmedo o interior de la montaña donde muere y renace el Dios del Maíz; las columnas son un claro ejemplo del árbol florido que se levanta al interior del lugar sobrenatural, el mensaje transmitía que el salón central de D6-15 era un palacio o santuario de fuertes preceptos religiosos. En las primeras décadas del siglo viII, el culto al Dios del Maíz-Cacao como árbol florido es definitivamente raro en este sector de la zona Puuc. El programa artístico y escultórico implementado por el señor principal de D6-15 fue complejo, en el sentido de incorporar numerosos elementos simbólicos que encierran varios temas sobre la apoteosis del dios agrario.

\section{Discusión}

Los datos asentados en el presente trabajo, según las propias fuentes procedentes de los sitios mencionados, aportan información trascendente en las concepciones políticas y culturales de la región Puuc. Dentro de las contribuciones presentadas, es destacable el papel de los sajales de Xcalumkín y Xcochá al personificar a la Serpiente de Guerra; la ausencia de soberanos con grado de rey llevó a los sajales a desplegar autoridad, liderazgo y jerarquía social en buena parte del Puuc Noroccidental al empoderarse con los atributos de la entidad militar. La situación de Itzimté Bolonchén es totalmente opuesta, ya que los mandatarios retratados en las Estelas 1 y 7 y el Dintel 2, más allá de personificar a la Serpiente de Guerra, participan como señores divinos, además de mostrar superioridad hegemónica sobre varios asentamientos de las serranías campechanas. Sin embargo, la producción escrituraria de los mayas del Puuc es escasa, pues se limita a unas cuantas décadas del siglo viII, y la relación sajal-Serpiente de Guerra todavía no es determinante. En este sentido, la plástica por incisión que decora un vaso de origen desconocido (K9272) apoya fuertemente la teoría que hemos venido sugiriendo, a pesar de no contar con algún tipo de datación que facilite la fecha precisa en que se fabricó la vasija. En la imagen sobresale un personaje disfrazado como la Serpiente de Guerra, a su izquierda hay un personaje diminuto y voluminoso, un enano; en el flanco derecho está otro individuo de pie con marcadas alteraciones físicas o gibosidad (Figura 10). 

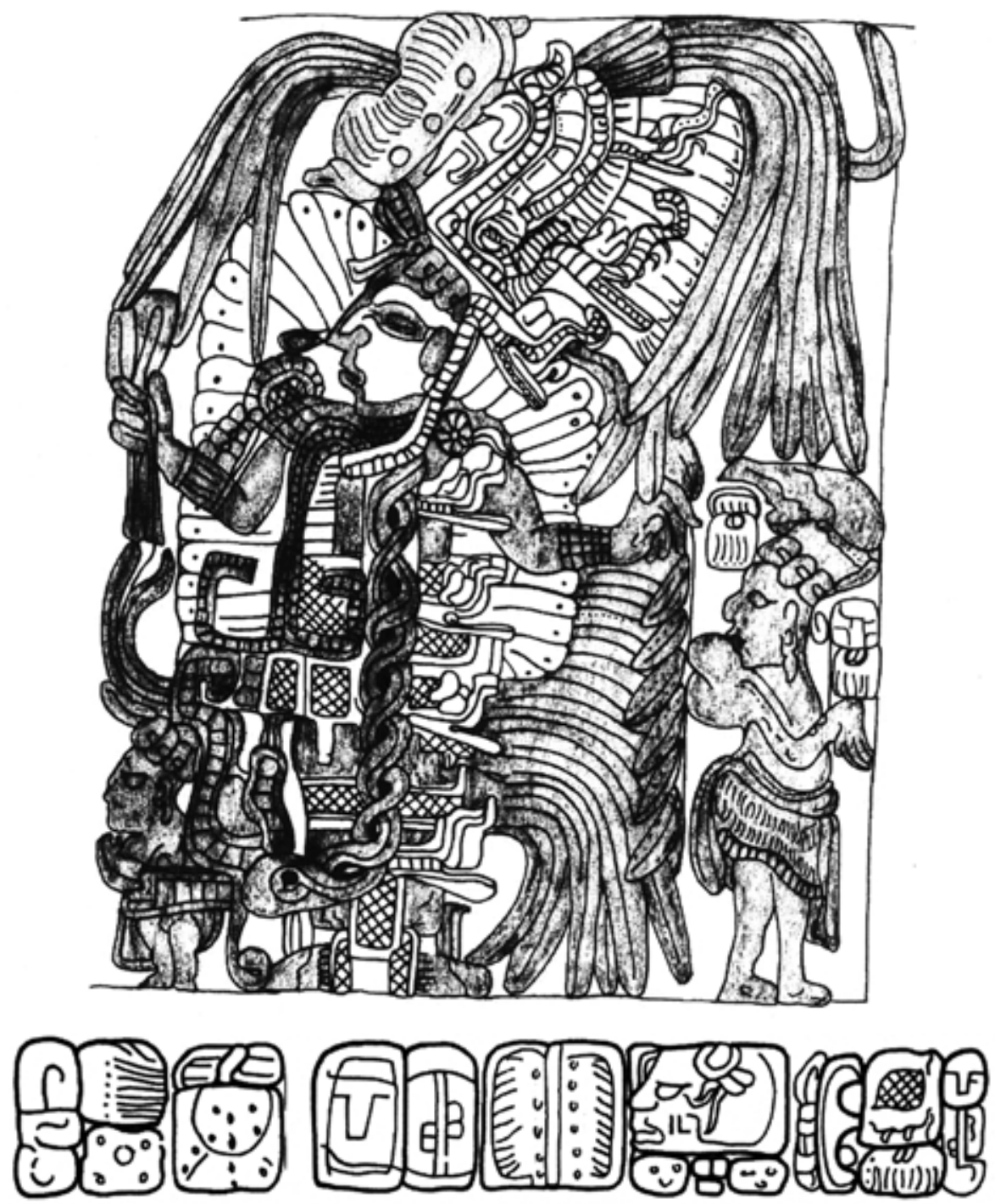

Figura 10. Detalle del vaso K9272 que muestra al personaje principal y sus acompañantes. El antropónimo está presente en la Secuencia Primaria Estándar, IK'-ki sa-ja-la u-k’a-ba-a', “su nombre es Ik' Sajal” (Dibujos: Azael García).

De las fauces abiertas del casco de serpiente surge una enorme baya de lirio acuático, prácticamente idéntica a las representadas en los yelmos de los sajales de las Jambas 1,4 y 5 de Xcalumkín y de la Columna 1 de Xcochá. Del maxilar inferior de la máscara de reptil emerge una gigantesca cuerda torcida que concluye en una pronunciada cabeza de sierpe que sirve de atuendo al enano, la 
cuerda torcida es el cuerpo del ofidio, semejante al cuerpo-cuerda de la serpiente que forma parte de la parafernalia del mandatario representado en la Estela 1 de Itzimté Bolonchén (Figura 7a). El texto jeroglífico inscrito en el borde del vaso corresponde a la Secuencia Primaria Estándar, y es aquí donde se encuentra el antropónimo del personaje que caracteriza a la fiera sierpe, el texto dice: $y$ - $u k^{\prime}-i b$ tzih-[il] ik' sajal u-k'aba', "es el vaso para beber (cacao) fresco, su nombre es Ik' Sajal". ${ }^{15}$ (Figura 10). Esta aportación ofrece más indicios para sostener que varios sajales del Puuc Temprano reivindicaron su posición social al mostrarse públicamente como la Serpiente de Guerra, y es casi seguro que la vasija K9272 fuera elaborada en algún taller del noreste de Campeche, en el sector en discusión, entre 720 y 771 .

Así bien, faltaría llevar a cabo estudios iconográficos en varios monumentos Puuc de origen desconocido donde es evidente la personificación de los mandatarios retratados con la evocación del numen militar; por ejemplo, una jamba ubicada en una colección particular muestra numerosas semejanzas con el arte en piedra de Xcalumkín (Mayer, 1980: 73); la columna esculpida ubicada en el Museo Metropolitano de Nueva York; la columna adquirida por el Museo de Arte de Worcester, Massachusetts; la Columna 1 de Yaxcabakal, del Museo de Arquitectura Maya, Campeche, además de una de las columnas más elaboradas y vistosas de arte Puuc, depositada en el Museo Etnológico de Berlín (Mayer, 1981: 3; Mills, 1985: 53; Pablo, 1993: 239; DesMeules y Foias, 2016).

En otro punto, el glifo emblema k'ihn ajaw de Xcalumkín y el gran cartucho jeroglífico de la Estela 7 de Itzimté se enlazan en tiempo y espacio en las tierras noroccidentales del Puuc en las primeras décadas del siglo vil al compartir un signo que podría tratarse de un préstamo cultural que identificara a alguna entidad política, muy probablemente Piedras Negras, en calidad de pequeños sitios subsidiarios con la intención de representar diplomáticamente a la enorme capital del Usumacinta; por otra parte, podría aludir a una entidad política o espacio físico de la región no determinado. El tema iconográfico también converge de manera aleatoria entre ambas demarcaciones al divulgar a la Serpiente de Guerra como una vía de propaganda política para afianzar y consolidar sus intereses territoriales, ideológicos o culturales en general. No obstante, es notoria la presencia de la región de Piedras Negras en Xcalumkín; más allá de las evidencias iconográficas antes señaladas, los complejos registros k'ihn ha' y k'inh ajaw parecen formar parte de una lejana red de influencia política. Es verdad que el tallador del Panel 3 y la Cornisa I no figura entre las rubricas de la región de Piedras Negras y, en este rubro, el estilo caligráfico del escultor de Xcalumkín difiere totalmente de

\footnotetext{
${ }^{15}$ En escritura jeroglífica maya, en contextos no calendáricos, el logograma IK' "viento" está compuesto por el signo principal T503 y el afijo T23, ambos elementos forman IK' "viento". En K9272 el afijo corresponde a una versión local de T102. Afortunadamente, en este mismo contexto sabemos que debe leerse IK' porque en la inscripción vertical de la misma vasija (no mostrada aquí) se repite el nominal nuevamente y en esta ocasión se muestra de manera convencional la secuencia T503-T23. De hecho, el nombre completo del personaje principal en K9272 es Bajlaj Ik' “Agitador del Viento".
} 
la tradición ribereña; es decir, la inscripción AJ-k'i-K'IN-ni-a es una versión única hasta ahora atestiguada en las serranías campechanas. Por lo tanto, el origen de k'ihn ha' y k'ihn ajaw es problemático al tratar de encontrar una explicación sensata que justifique su presencia en Xcalumkín durante el Puuc Temprano. Ante este panorama, sólo podemos mencionar de forma hipotética algunos motivos que pueden llegar a esclarecer la participación de los dos compuestos jeroglíficos fuera de la región del Usumacinta. Carlos Pallán (2009b: 282-283) ya había mencionado con antelación que la presencia tardía de k'ihn ha' (o tal vez k'ihn ajaw) en Edzná (869? d.C.) se debió a lejanos acuerdos y alianzas políticas entabladas entre Calakmul (Kan'ul), Moral Reforma y Piedras Negras entre los años 662 al 685, una configuración de sitios aliados durante el reinado de Yuhknoom el Grande, labor que pudo facilitar vínculos e interacciones políticas a nivel transregional, pues en este periodo Edzná también formaba parte de la enorme red hegemónica del reino de la Cabeza de Serpiente.

La siguiente vía de explicación, señala que al final del reinado de Yonal Ahk II, Piedras Negras sufrió un revés militar cuando Chaak Suutz', sajal y yajaw k'ahk' de Palenque, dirigió una agresiva campaña castrense en contra de k'ihn ha', entidad política subordinada de Piedras Negras, hacia el 725 (Martin y Grube, 2008: 146; Bernal, 2011: 321). Tres años más tarde de aquel episodio beligerante aparecen las primeras anotaciones calendáricas talladas en los principales conjuntos residenciales de Xcalumkín, además de k'ihn ha' y k'ihn ajaw en el Edificio Sur del Grupo de los Jeroglíficos. En un marco hipotético podemos pensar que en algún momento de inestabilidad política y social, k'ihn ha' devastado por el ataque palencano buscó nuevas entidades y sedes aliadas; éste pudo ser un motivo de exilio y repatriación de gente subordinada y afiliada a la nobleza de Piedras Negras. Tal situación pudo promover un lejano desplazamiento humano hacia el noreste de Campeche, entre ellos varios sajales que sustituyeron a la antigua casa reinante de la fase Xcalumkín Temprano, dando como resultado una alianza con la isla de Jaina (García Nava, 2017; s/f), proceso de coyuntura que dio un nuevo giro entre los mayas del Puuc.

En otros asuntos, Nah Ho' Chan Bob, registrado en el Dintel 1 de Itzimté, es una versión local que determina el ambiente y paisaje de un lugar sobrenatural perfumado y engalanado por flores, una geografía sagrada relacionada con el crecimiento del maíz y el renacimiento del sol; en otras palabras, es un lugar para ungir y consagrar la vitalidad dinástica de los soberanos mayas para alcanzar su futura apoteosis. La otra toponimia, Wuk Chit K'an Nal, era el nombre que recibía en la antigüiedad el Edificio de las Columnas Labradas de Xculoc; el programa ideológico fue bastante ambicioso al incorporar mitos y creencias que se tradujeron en arte consagrado; el culto al Dios del Maíz-Cacao como árbol florido refrenda la identidad sobrenatural del mandatario propietario del inmueble. En el registro jeroglífico serrano, estas anotaciones toponímicas entraron en vigor en la primera mitad del siglo vill; los dignatarios del periodo se apoyaron en el pensamiento religioso para demostrar su proximidad con lo divino, ejerciendo 
liderazgo y control político-social. De igual forma, la difusión de estos lugares sobrenaturales coincidiría con la presencia de forasteros asociados a las Tierras Bajas.

\section{Comentarios finales}

La evidencia presentada, si bien no es exhaustiva, muestra aspectos de la vida cortesana en este pequeño sector de la zona Puuc al hacer uso de atuendos militares, topónimos y títulos emblema. Los mandatarios que hemos identificado en varios momentos con el cargo-rango de sajal posiblemente adoptaron nuevas formas y expresiones de gobierno conforme se consolidaba el estilo Puuc Temprano: un sajalato o pequeños señoríos independientes que experimentaron un gobierno comunal en un corto periodo de tiempo (728-771 d.C.). La Serpiente de Guerra evocaría, según nuestras indagaciones, expansión territorial, control político y un medio de poder ideológico. Los datos aportados sugieren provisionalmente una movilización de capital humano procedente del Usumacinta para establecerse en el noreste de Campeche en el apogeo estilístico Puuc Temprano. Por desgracia, los estudios arqueológicos son escasos todavía en esta importante región del área maya y seguiremos en espera de nuevas investigaciones que vengan a dar luz en el sector de las serranías de Campeche.

\section{Bibliografía}

Andrews, George

1986 Los estilos arquitectónicos del Puuc. Una nueva apreciació. Traducción de Antonio Benavides C. México: Instituto Nacional de Antropología e Historia.

Ara, Domingo de

1986 Vocabulario de Lengua Tzendal según el Orden de Copanabastla. Mario H. Ruz (ed.). México: Instituto de Investigaciones Filológicas, Centro de Estudios Mayas.

Arzápalo Marín, Ramón

1995 Calepino de Motul. Diccionario Maya-Español. Tomo I. México: Universidad Nacional Autónoma de México.

Aulie, Wilbur y Evelyn Aulie

1978 Diccionario ch'ol-español, español-ch'ol. México: Instituto Linguístico de Verano (Serie de vocabularios y diccionarios indígenas, 21).

Barrera Vásquez, Alfredo

1976 "La Ceiba-Cocodrilo", Anales del Instituto Nacional de Antropología e Historia, V (53): 187-208. 
Barrera Vásquez, Alfredo (coord.)

1980 Diccionario maya-español, español-maya. Mérida: Cordemex.

Becquelin, Pierre

2002 "Linajes y poder político en la civilización Puuc: el ejemplo de la región de Xculoc”, Estudios de Cultura Maya, XXII: 113-123. Dol: https://doi.org/iifl. ecm.2002.22.411.

Becquelin, Pierre, Dominique Michelet y Antonio Benavides Castillo

2011 “¿Una organización dualista en Xcalumkín antes del inicio del estilo Puuc Temprano?”, Mexicon, XXXIII (2): 38-46.

Benavides Castillo, Antonio

2000 "Restauración de emergencia en Ichmac, Campeche", Los Investigadores de la Cultura Maya, 8 (I): 197-211.

Benavides Castillo, Antonio, Sara Novelo Osorno y Carlos Pallán Gayol

2011 "El tiempo de las portadas jeroglíficas en la región Puuc", ponencia presentada en el marco de la VII Mesa Redonda de Palenque: "Los Mayas y las Concepciones del Tiempo”. Del 27 de noviembre al 2 de diciembre de 2011.

Bernal Romero, Guillermo

2011 "El señorío de Palenque durante la era de K’inich Janaab’ Pakal y K'inich Kan B'ahlam (615-702 d.C.)", tesis de doctorado en Estudios Mesoamericanos. México: Universidad Nacional Autónoma de México, Facultad de Filosofía y Letras, Instituto de Investigaciones Filológicas.

Bíró, Péter

2012 "Politics in the Western Maya Region (II): The Emblem Glyphs", Estudios de Cultura Maya, XXXIX: 31-66. Dor: https://doi.org/10.19130/iifl.ecm.2012.39.58.

2016 "Emblem Glyphs in Classic Maya Inscriptions: From Single to Double Ones as a Means of Place of Origin, Memory and Diaspora”, Places of Power and Memory in Mesoamerica's Past and Present How Sites, Toponyms and Landscapes Shape History and Remembrance, pp. 124-158, Daniel Graña-Behrens (ed.). Berlin: Ibero-Amerikanisches Institut, Preußischer Kulturbesitz (Estudios Indiana, 9).

Boot, Erik

1996 "Notes on the Inscriptions at Xcalumkin, Campeche, Mexico", Yumtzilob, 8 (2): 124-148.

2009 The Updated Preliminary Classic Maya-English, English-Classic Maya Vocabulary of Hieroglyphic Readings. Disponible en: < http://www.mesoweb.com/resources/ vocabulary/Vocabulary-2009.01.pdf $>$ [consultada el 12 de mayo de 2019].

2010 "An Oxkintok Region Vessel: An Analysis of the Hieroglyphic Texts", Mesoweb. Disponible en: <http://www.mesoweb.com/articles/boot/Oxkintok. pdf $>$ [consultada el 19 de enero de 2020].

Bricker, Victoria R., Eleuterio Po'ot y Ofelia Dzul

1998 A Dictionary of the Maya Language. As Spoken in Hocabá, Yucatán. Salt Lake City: University of Utah Press. 
DesMeules, Hadley y Antonia Foias

2016 "Connections Between the Northern and Southern Maya: Perspectives from Three Unprovenanced Puuc Columns", Mexicon, XXXVIII: 150-156.

Esparza Olguín, Octavio y Erik Velásquez García

2013 "The YUK Logogram in Maya Hieroglyphic Writing", The PARI Journal, XIV (1): 1-5. Disponible en: <http://www.precolumbia.org/pari/journal/archive/ PARI1401.pdf $>$ [consultada el 22 de julio de 2019].

García Campillo, José M.

1995 "Antroponimia y toponimia en las inscripciones mayas de Yucatán”, tesis de doctorado en Geografía e Historia. Madrid: Universidad Complutense.

García Juárez, Sara Isabel

2015 "La historia de Piedras Negras a través de sus inscripciones jeroglíficas: auge y ocaso del linaje de las Tortugas", tesis de licenciatura en Historia. México: Universidad Nacional Autónoma de México, Facultad de Filosofía y Letras, Colegio de Historia.

García Nava, D. Azael

2017 "Historia antigua de Xcalumkín a través de sus inscripciones jeroglíficas", tesis de maestría en Estudios Mesoamericanos. México: Universidad Nacional Autónoma de México, Facultad de Filosofía y Letras, Instituto de Investigaciones Filológicas.

2018 "Nuevos datos epigráficos en monumentos de piedra sobre la región de Xcalumkín, Campeche”, Glifos, 16: 22-29. Disponible en: <https:/issuu.com/ museosinahcampeche/docs/16> [consultado el 12 de mayo de 2019].

s/f "La casa del sabio: una aproximación a la organización política en Xcalumkín durante la fase Puuc Temprano", Guerras, jerarquías políticas y poder en la sociedad maya del periodo Clásico. Guillermo Bernal Romero y Octavio Esparza Olguín (eds.). México: Universidad Nacional Autónoma de México, Instituto de Investigaciones Filológicas, Centro de Estudios Mayas.

Gendrop, Paul

1983 Los estilos Río Bec, Chenes y Puuc en la arquitectura maya. México: Universidad Nacional Autónoma de México.

Graham, Ian y Eric Von Euw

1992 Corpus of Maya Hieroglyphic Inscriptions. Vol. 4, parte 3, Uxmal y Xcalumkín. Cambridge: Peabody Museum of Archaeology and Ethnology, Harvard University.

Graña-Behrens, Daniel

2002 "Die Maya-Inschriften aus Nordwest Yukatan”, tesis de doctorado en Filosofía. Bonn: Universidad de Bonn.

2016 "The Hieroglyphic Inscriptions of Itzimte-Bolonchen, Campeche, Mexico: Rulers and Political Affaires from Burned Stones", The Long Silence. Vol. 2. Itzimte and its Neighbors: An Architectural Survey of Maya Puuc Ruins in Nor- 
theastern Campeche, México, pp. 165-188. Stephan Merk (ed.). Norderstedt: BoD.

2018 "New Evidence for Political Hierarchy and Power in the Northern Maya Lowlands (A.D. 600-1000)", Ancient Mesoamerica, 29: 171-195.

Grube, Nikolai

2003 "Hieroglyphic Inscriptions from Northwest Yucatan: An Update of Recent Research”, Escondido en la Selva, pp. 339-370, Hanns J. Prem (ed.). México: Instituto Nacional de Antropología e Historia, Universidad de Bonn.

Houston, Stephen y David Stuart

1996 "Of Gods, Glyphs and Kings: Divinity and Rulership among the Classic Maya", Antiquity, 70: 289-312. Dor: https://doi.org/10.1017/S0003598X00083289.

Kaufman, Terrence

2003 A Preliminary Mayan Etymological Dictonary. Disponible en FAmsi: <http:// www.famsi.org/reports/01051/index.html> [consultada el 12 de mayo de 2019].

Kerr, Justin

s.f. Maya Vase Data Base. An archive of rollout photographs. Disponible en: < http:// research.mayavase.com/kerrmaya.html > [consultada el 6 de octubre de 2019].

Kowalski, Jeff Karl

1994 "The Puuc as Seen from Uxmal”, Hidden among the Hills. Maya Archaeology of the Northwest Yucatan Peninsula, Acta Mesoamericana, 7: 93-120, Hanns J. Prem (ed.). Markt Schwaben: Verlag Von Flemming.

Lacadena García-Gallo, Alfonso

2006 "Excavaciones en Machaquilá. Temporada 2005: el recinto cuadrilobulado de la Plaza A", Reporte 20, Atlas Arqueológico de Guatemala, pp. 74-123. Guatemala: Dirección General del Patrimonio Cultural y Natural, Ministerio de Cultura y Deportes.

Lacadena García-Gallo, Alfonso y Søren Wichmann

2004 "On the Representation of the Glottal Stop in Maya Writing", The Linguistics of Maya Writing, pp. 103-162, Søren Wichmann (ed.). Salt Lake City: University of Utah Press.

Looper, Matthew G.

2003 Lightning Warriors. Maya Art and Kingship at Quirigua. Austin: University of Texas Press.

López Austin, Alfredo

1994 Tamoanchan y Tlalocan. México: Fondo de Cultura Económica. 
López Austin, Alfredo y Leonardo López Luján

2009 Monte sagrado-Templo mayor: el cerro y la pirámide en la tradición religiosa mesoamericana. México: Universidad Nacional Autónoma de México, Instituto Nacional de Antropología e Historia.

Martin, Simon

2001 "La gran potencia occidental: los mayas y Teotihuacán”, Los mayas. Una civilización milenaria, pp. 99-111, Nikolai Grube (ed.). Colonia: Könemann.

2006 "Cacaw in Ancient Maya Religion. First Fruit from the Maize Tree and Other Tales from the Underworld", Chocolate in Mesoamerica: A Cultural History of Cacao, pp. 154-183, Cameron McNeil (ed.). Gainesville: University Press of Florida.

2012 “Carved Bowl”, Ancient Maya Art at Dumbarton Oaks, pp. 108-119, Joanne Pillsbury, Miriam Doutriaux, Reiko Ishihara-Brito y Alexandre Tokovinine (eds.). Washington, D.C.: Dumbarton Oaks Research Library and Collection (Pre-Columbian Art at Dumbarton Oaks, 4).

Martin Simon y Nikolai Grube

2008 Chronicle of the Maya Kings and Queens. Londres: Thames and Hudson.

Mayer, Karl H.

1980 Maya Monuments: Sculptures of Unknown Provenance in United States. Ramona: Acoma Books.

1981 Classic Maya: Relief Columns. Ramona: Acoma Books.

1999 "Lintel 2 from the Maya Ruins of Itzimte, Campeche”, Mexicon, XXI: 94-95.

2012 “An Unprovenanced Maya Relief Doorway Column”, Mexicon, XXXIV: 1-3.

Michelet, Dominique y Pierre Becquelin

1995 "Elementos políticos y religiosos de un sector de la región Puuc occidental: su identificación e interpretación”, Religión y sociedad en el área maya, pp. 109-134, Carmen Varela, Juán Luis Bonor y María Yolanda Fernández (coords.). Madrid: Sociedad Española de Estudios Mayas.

Michelet, Dominique y Charlotte Arnauld

2006 "Del arraigo mediante el culto a los ancestros a la reivindicación de un origen extranjero", Nuevas ciudades, nuevas patrias. Fundación y relocalización de ciudades en Mesoamérica y el Mediterráneo antiguo, pp. 65-92, María Josefa Iglesias, Rogelio Valencia y Andrés Ciudad Ruíz (eds.). Madrid: Sociedad Española de Estudios Mayas.

Michelet, Dominique, Pierre Becquelin, Antonio Benavides, Sara Dzul Góngora y Emily González Gómez

2007 "Informe sobre los trabajos de la temporada de campo 2007, Xcalumkín (Campeche, México)”, reporte inédito fechado el 13 de noviembre de 2008. México: Instituto Nacional de Antropología e Historia, Consejo de Arqueología.

Miller, Mary y Simon Martin

2004 Courtly Art of the Ancient Maya. Londres: Thames and Hudson. 
Mills, Lawrence

1985 "A Study of Carved Columns Associated with Puuc Architecture: A Progress Report”, Arquitectura y arqueología: metodologías en la cronología de Yucatán, pp. 51-55, George Andrews y Paul Gendrop (eds.). México: Centro de Estudios Mexicanos y Centroamericanos.

Montgomery, John

s.f. The John Montgomery Drawing Collection. Disponible en Famsi: <http://www. famsi.org/research/montgomery/index.html> [consultada el 15 de septiembre de 2019].

Nielsen, Jesper y Christophe Helmke

2008 "Spearthrower Owl Hill: A Toponym at Atetelco, Teotihuacan", Latin American Antiquity, 19 (4): 459-474. Dol: https://doi.org/10.1017/S1045663500004387.

Novelo Osorno, Sara y Antonio Benavides C.

2018 “Dos columnas con relieves de Xchan, Campeche”, Glifos, 5 (18): 16-31. Disponible en: <https://issuu.com/museosinahcampeche/docs/18> [consultada el 19 de marzo de 2019].

Pablo Aguilera, María del Mar

1993 "Algunas columnas antropomorfas en la mitad occidental del área Puuc. Particular referencia al sitio de Oxkintok", Perspectivas antropológicas en el mundo maya, pp. 237-252, María Josefa Iglesias y Francesc Ligorred (eds.). Girona: Sociedad Española de Estudios Mayas, Universidad Complutense de Madrid.

Pallán Gayol, Carlos

2009a "The Many Faces of Chaahk: Exploring the Role of a Complex and Fluid Entity within Myth, Religion and Politics", The Maya and their Sacred Narratives: Text and Context in Maya Mythologies, Proceedings of the 12th European Maya Conference, pp. 17-40, Genevieve Le Fort, Raphael Gardiol, Sebastian Matteo y Christophe Helmke (eds.). Alemania: Verlag Anton Saurwetn.

2009b "Secuencia dinástica, glifos-emblema y topónimos en las inscripciones jeroglíficas de Edzná, Campeche (600-900 d.C.): implicaciones históricas", tesis de maestría en Estudios Mesoamericanos. México: Universidad Nacional Autónoma de México, Facultad de Filosofía y Letras, Instituto de Investigaciones Filológicas.

Patrois, Julie

2008 Etude iconographique des sculptures du nord de la péninsule du Yucatán á l'époque classique. Oxford: BAR (Monographs in American Archaeology, 20).

Pavón Abreu, Raúl

1942 Guía del museo arqueológico, etnográfico e histórico del estado. Campeche: Gobierno del Estado.

Piña Chán, Román

1968 Jaina: la casa en el agua. México: Instituto Nacional de Antropología e Historia. 
Piña Chán, Román

1996 "Las Figurillas de Jaina”, Arqueología Mexicana, 18: 52-59.

Pollock, Harry E. D.

1980 The Puuc. An Architectural Survey of the Hill Country of Yucatan and Northern Campeche, Mexico. Cambridge: Universidad de Harvard, Museo Peabody de Arqueología y Etnología.

Proskouriakoff, Tatiana

1950 A Study of Classic Maya Sculpture. Washington: Carnegie Institution of Washington (Publication 593).

Sosa López, Domingo Esteban, María del Carmen Tuy Tococh, Jesús Aceytuno Felipe y José Sanic Chanchavac

2003 Vocabulario mopán. Guatemala: Academia de Lenguas Mayas de Guatemala.

Stone, Andrea y Marc Zender

2011 Reading Maya Art. A Hieroglyphic Guide to Ancient Maya Painting and Sculpture. Londres: Thames and Hudson.

Stuart, David

1985 "New Epigraphic Evidence of Late Classic Maya Political Organization". Manuscrito inédito. Disponible en: <https://www.academia.edu/21665699/

New_Epigraphic_Evidence_of_Late_Classic_Maya_Political_Organization_1985_ms._> [consultado el 22 de julio de 2019].

2000 "The Arrival of Strangers", Teotihuacan and Tollan in Classic Maya History, Mesoamerica's Classic Heritage: From Teotihuacan to the Aztecs, pp. 465-514, David Carrasco, Lindsay Jones y Scott Sessions (eds.). Boulder: University Press of Colorado.

2001 “Earthquake!", Mesoweb <http://www.mesoweb.com/stuart/notes/Earthquake. pdf $>$ [consultada el 12 de mayo de 2019].

2004 "The Paw Stone: The Place Name of Piedras Negras, Guatemala", The PARI Journal 4 (3): 1-6. Disponible en: <http://www.mesoweb.com/pari/journal/ archive/PARI0403.pdf $>$ [consultada el 19 de enero de 2020].

2005 The Inscriptions from Temple XIX at Palenque. A Commentary. San Francisco: The Pre-Columbian Art Research Institute.

2009 "The Symbolism of Zacpetén, Altar 1", The Kowoj: Identity, Migrations and Geopolitics in Late Postclassic Peten, Guatemala, pp. 317-326, Prudence Rice y Don Rice (eds.). Boulder: University of Colorado Press.

Stuart, David y Stephen Houston

1994 Classic Maya Place Names. Washington: Dumbarton Oaks (Studies in Pre-Columbian Art and Architecture, 33).

Taube, Karl

1992

"The Temple of Quetzalcoatl and the Cult of Sacred War at Teotihuacan”, RES: Anthropology and Aesthetics, 21: 53-87. Dol: https://doi.org/10.1086/RES$\mathrm{v} 21 \mathrm{n} 1 \mathrm{~ms} 20166842$. 
Taube, Karl

2004 "Flower Mountain: Concepts of Life, Beauty, and Paradise among the Classic Maya”, RES: Anthropology and Aesthetics, 45: 69-98. Dol: https://doi. org/10.1086/RESv45n1ms20167622.

2005 "The Symbolism of Jade in Classic Maya Religion”, Ancient Mesoamerica, 16 (1): 23-50. DoI: https://doi.org/10.1017/S0956536105050017.

2016 "Through a Glass, Brightly: Recent Investigations Concerning Mirrors and Scrying in Ancient and Contemporary Mesoamerica", Manufactured Light. Mirrors in the Mesoamerican Realm, pp. 285-314, Emiliano Gallaga y Marc Blainey (eds.). Boulder: University Press of Colorado.

Teufel, Stefanie

2004 "Die Monumental skulpturen von Piedras Negras, Petén, Guatemala: Eine hieroglyphische und ikonographisch-ikonologische Analyse", tesis de doctorado en Filosofía. Bonn: Rheinischen Friedrich-Wilhelms, Universität zu Bonn.

Thompson, Eric

1965 Arqueología Maya. México: Editorial Diana.

Tokovinine, Alexandre

2012 "Fluted and Incised Bowl", Ancient Maya Art at Dumbarton Oaks, pp. 121-129, Joanne Pillsbury, Miriam Doutriaux, Reiko Ishihara-Brito y Alexandre Tokovinine (eds.). Washington: Dumbarton Oaks (Pre-Columbian Art at Dumbarton Oaks, 4).

Ulrich, F. Matthew y Rosemary Ulrich

1976 Diccionario maya mopán. Guatemala: Instituto Lingüístico de Verano.

Velásquez García, Erik

2010 "Los Dioses Remeros mayas y sus posibles contrapartes nahuas", Acta Mesoamericana 22, The Maya and the Neighbours. Internal and External Contacts Through Time, pp. 115-131, Markt Schwaben: Verlag Anton Saurwein.

Velásquez García, Erik y Octavio Q. Esparza Olguín

2013 "El sacudidor de ciudades. Un jeroglífico maya para mover, temblar o terremoto”, Arqueología Mexicana, 123: 84-87.

Vidal, Cristina y Gaspar Muñoz

1997 "La arquitectura de las ciudades mayas del área Puuc, Yucatán”, X Simposio de Investigaciones Arqueológicas en Guatemala, 1996, pp. 360-376, Juan Pedro Laporte y Héctor Escobedo (eds.). Guatemala: Museo Nacional de Arqueología y Etnología.

Von Euw, Eric

1977 Corpus of Maya Hieroglyphic Inscriptions, Vol. 4, Pt. 1: Itzimte, Pixoy, and Tzum. Cambridge: Peabody Museum of Archaeology and Ethnology, Harvard University. 


\begin{abstract}
Wagner, Elisabeth
2000 "An Alternative View on the Meaning and Function of Structure 10L-22a Copán, Honduras", Acta Mesoamericana 10, The Sacred and the Profane. Architecture and Identity in the Maya Lowlands, pp. 25-49, Pierre Colas, Kai Delvendahl, Markus Kuhnert y Annette Schubart (eds.). Markt Schwaben: Verlag Anton Saurwein.

Zender, Marc

2002 "The Toponyms of El Cayo, Piedras Negras, and La Mar", Heart of Creation: The Mesoamerican World and the Legacy of Linda Schele, pp. 166-184, Andrea Stone (ed.). Tuscaloosa: The University of Alabama Press.

2010 "Baj "Hammer" and Related Affective Verbs in Classic Mayan”, The PARI Journal, XI (2): 1-10.

Źrałka, Jarosław, Christophe Helmke, Simon Martin, Wiesław Koszkul y Juan Luis Velásquez 2018 "The Monolithic Monuments of Nakum, Guatemala", PARI Journal, 19 (1): 1-28. Disponible en: < http://www.precolumbia.org/pari/journal/archive/PARI1901. pdf $>$ [consultada el 22 de julio de 2019].
\end{abstract}

David Azael García Nava. Mexicano. Licenciado en Etnohistoria por la Escuela Nacional de Antropología e Historia y maestro en Estudios Mesoamericanos por la Universidad Nacional Autónoma de México. Su especialidad son los estudios de epigrafía maya en el sector Puuc Noroccidental de las Tierras Bajas del norte, durante el Clásico Tardío. Sus principales líneas de investigación son la organización política, los símbolos de poder y las expresiones religiosas entre los mayas antiguos y actualmente desarrolla el proyecto "Edificios de poder: expresiones artísticas y escriturarias en los monumentos esculpidos de estilo Puuc (728-771 d.C.)". Entre sus publicaciones puede mencionarse "La casa del sabio: una aproximación a la organización política en Xcalumkín durante la fase Puuc Temprano”.

azaelgarcia_09@yahoo.com.mx 